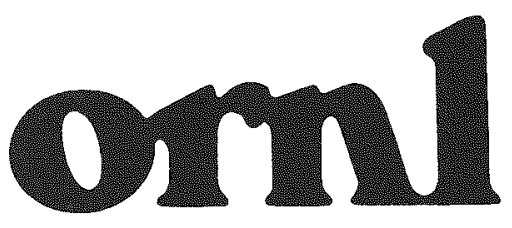

OAK RIDGE NATIONAL LABORATORY

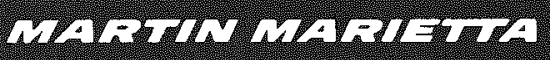

$D R-1090 \%$

$$
I-21490
$$

\title{
Development and Characterization of Carbon-Bonded Carbon Fiber Insulation for Radioisotope Space Power Systems
}

G. C. Wei

J M Robbins
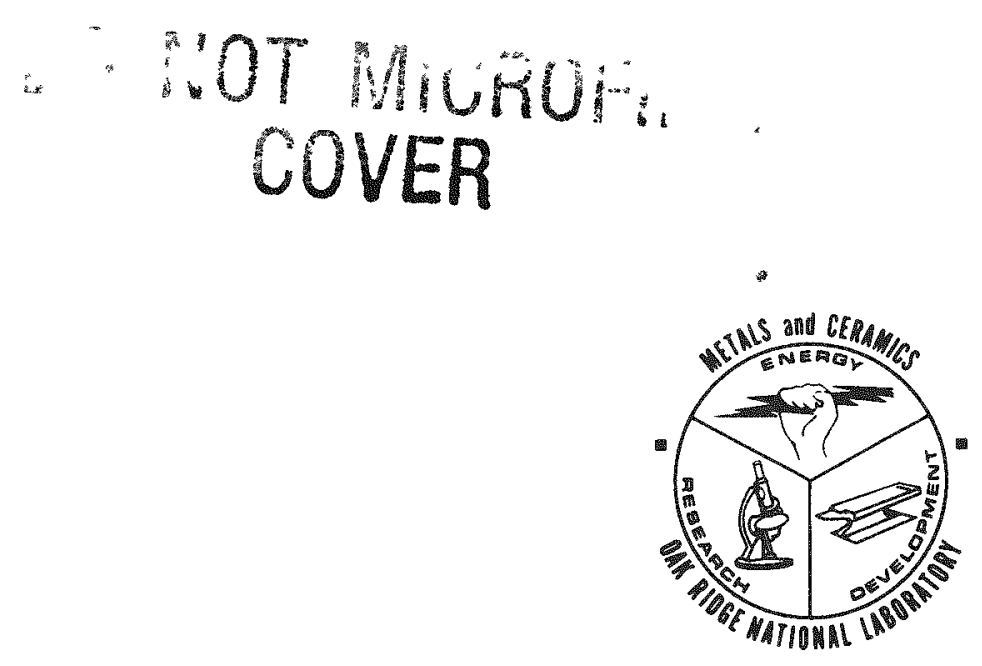

DPEAATED BY 


\section{DISCLAIMER}

This report was prepared as an account of work sponsored by an agency of the United States Government. Neither the United States Government nor any agency Thereof, nor any of their employees, makes any warranty, express or implied, or assumes any legal liability or responsibility for the accuracy, completeness, or usefulness of any information, apparatus, product, or process disclosed, or represents that its use would not infringe privately owned rights. Reference herein to any specific commercial product, process, or service by trade name, trademark, manufacturer, or otherwise does not necessarily constitute or imply its endorsement, recommendation, or favoring by the United States Government or any agency thereof. The views and opinions of authors expressed herein do not necessarily state or reflect those of the United States Government or any agency thereof. 


\section{DISCLAIMER}

Portions of this document may be illegible in electronic image products. Images are produced from the best available original document. 


\section{Printed in the United States of America. Available from National Technical Information Service \\ US. Department of Commerce 5285 Port Royal Road, Springfield, Virginia 22161 NTIS price codes-Printed Copy: A04 Microfiche A01}

This report was prepared as an account of work sponsored by an agency of the United States Government Nether the United States Government nor any agency thereof, nor any of their employees, makes any warranty, express or implied, or assumes any legal hability or responsibility for the accuracy, completeness, or usefulness of any information apparatus, product, or process disclosed, or represents that its use would not infringe privately owned rights Reference herein to any specific commercial product, process, or service by trade name, trademark, manufacturer, or otherwise, does not necessarily constitute or imply its endorsement, recommendation, or favoring by the United States Government or any agency thereof The views and opinions of authors expressed herein do not necessarily state or reflect those of the United States Government or any agency thereof

\section{NoT wi: : \\ SOVER}




\title{
DEVELOPMENT AND CHARACTERIZATION OF CARBON-BONDED CARBON FIBER INSULATION FOR RADIOISOTOPE SPACE POWER SYSTEMS
}

\author{
G. C. Wei and J M Robbins
}

Date Published: June 1985

NOTICE: This document contains information of a preliminary nature. It is subject to revision or correction and therefore does not represent a final report.

Prepared for DOE Office of Special Nuclear Projects

\author{
Prepared by the \\ OAK RIDGE NATIONAL LABORATORY \\ Oak Ridge, Tennessee 37831 \\ operated by \\ MARTIN MARIETTA ENERGY SYSTEMS, INC. \\ for the \\ U.S. DEPARTMENT OF ENERGY \\ under Contract No. DE-ACO5-840R21400
}




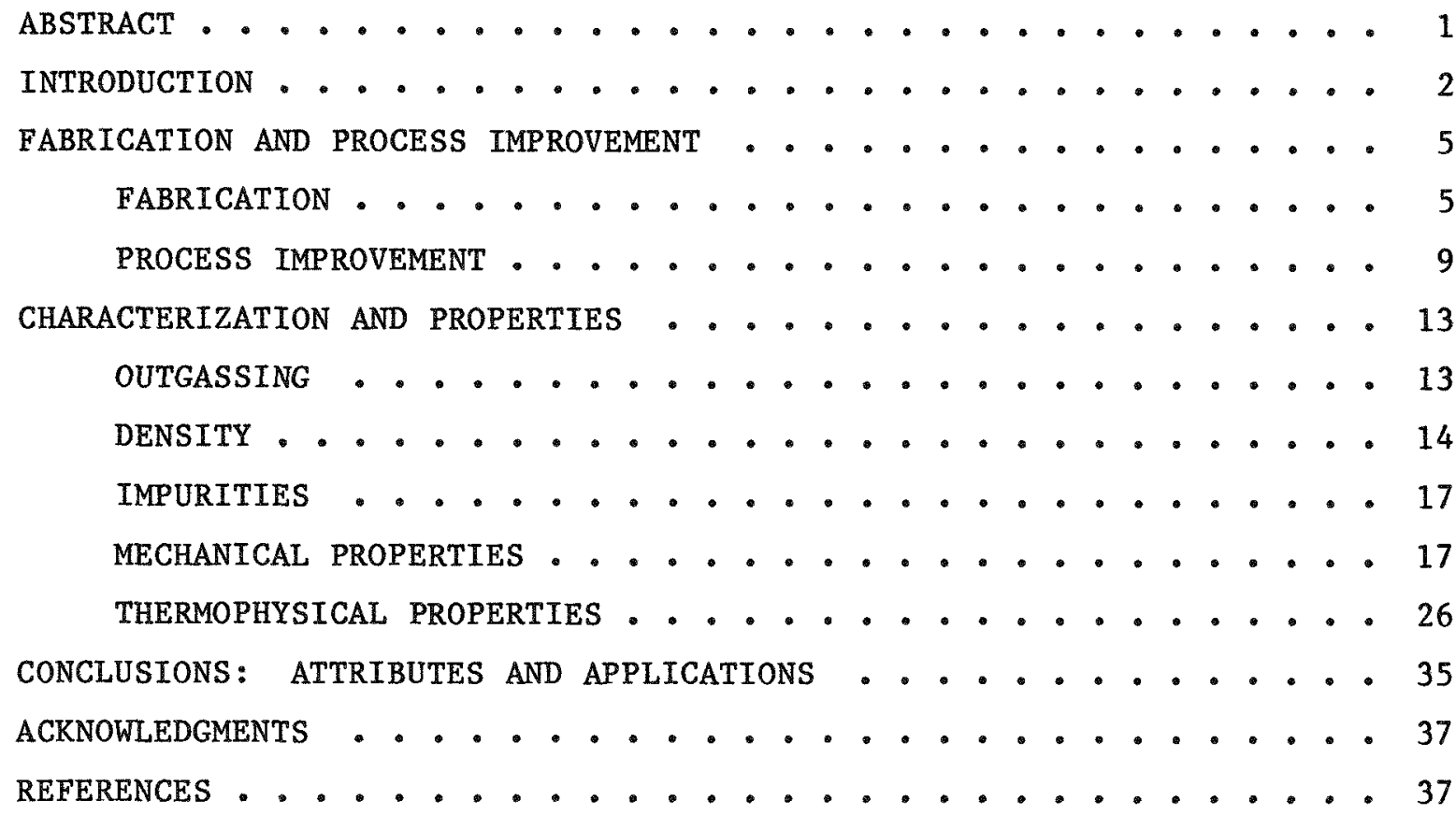

\section{DISCLAIMER}

This report was prepared as an account of work sponsored by an agency of the United States Government. Neither the United States Government nor any agency thereof, nor any of their employees, makes any warranty, express or implied, or assumes any legal liability or responsibility for the accuracy, completeness, or usefulness of any information, apparatus, product, or process disclosed, or represents that its use would not infringe privately owned rights. Reference herein to any specific commercial product, process, or service by trade name, trademark, manufacturer, or otherwise does not necessarily constitute or imply its endorsement, recommendation, or favoring by the United States Government or any agency thereof. The views and opinions of authors expressed herein do not necessarily state or reflect those of the United States Government or any agency thereof. 
DEVELOPMENT AND CHARACTERIZATION OF CARBON-BONDED CARBON FIBER INSULATION FOR RADIOTSOTOPE SPACE POWER SYSTEMS*

\author{
G. C. Wei and J M Robbins
}

\begin{abstract}
The Genera1-Purpose Heat Source (GPHS) is an improved radioisotope heat source for use in the thermoelectric generators for the 1986 Galileo and Ulysses (formerly International Solar Polar) Missions. The heat source uses a modular design, which makes it adaptable to a wide range of power levels. The GPHS employs a unique thermal insulation material, carbon-bonded carbon fiber (CBCF), to protect the fuel capsule and to help achieve the highest possible specific power.

The CBCF insulation developed for the GPHS is made from chopped rayon fiber about $10 \mu \mathrm{m}$ in diameter and $250 \mu \mathrm{m}$ long, which is carbonized and bonded with phenolic resin particles. The $\mathrm{CBCF}$ shapes, both tubes and plates, are formed in a multiple molding facility by vacuum molding a water slurry of the carbonized chopped-rayon fiber ( $54 \mathrm{wt} \%$ ) and phenolic resin (46 wt \%). The molded shapes are subsequently dried and cured. Final carbonization of the resin is at $1600^{\circ} \mathrm{C}$. Machining to close tolerances $( \pm 0.08 \mathrm{~mm})$ is accomplished by use of conventional tooling in conjunction with appropriate fixturing. The resulting material is an excellent lightweight insulation with a nominal density of $0.2 \mathrm{Mg} / \mathrm{m}^{3}$ and a thermal conductivity of $0.24 \mathrm{~W} /\left(\mathrm{m}^{\circ} \mathrm{K}\right)$ in vacuum at $2000^{\circ} \mathrm{C}$. Several attributes that make $\mathrm{CBCF}$ superior to other known high-temperature insulation materials for the GPHS application have been identified. It has the excellent attributes of light weight, low thermal conductivity, chemical compatibility, and high-temperature capabilities. The mechanical strength of $\mathrm{CBCF}$ insulation is satisfactory for the GPHS application; it has passed vibration tests simulating launch conditions.

At Oak Ridge National Laboratory the basic fabrication technique was refined to eliminate undesirable large pores and cracks often present in materials fabricated by earlier techniques. Also, processing was scaled up to increase the fabrication rate by a factor of 10 . The specific properties of the $\mathrm{CBCF}$ were tailored by adjusting material and processing variables to obtain the desired results. We report here how work on CBCF characterization and development conducted at ORNL from 1978 through 1980 has contributed to the GPHS program to meet the requirements of both the Galileo and Ulysses Missions.
\end{abstract}

* Research sponsored by the office of Special Nuclear Projects, office of Nuclear Energy, U.S. Department of Energy, under contract DE-AC05-840R21400 with Martin Marietta Energy Systems, Inc. 
INTRODUCTION

The 1986 Galileo and Ulysses Missions involve launching two spacecraft for scientific exploration beyond the earth's ecliptic plane, including the region near the sun's poles. A critical component of both spacecraft is the radioisotopic thermoelectric generator (RTG). The RTG is required to supply electricity for the scientific instruments aboard. It produces electrical power by converting the heat generated by a radioisotopic heat source called the General Purpose Heat Source (GPHS) into electrical energy through the thermoelectric effects of silicongermanium alloys. The heat source utilizes the heat produced by the selfabsorption of alpha particles in the ${ }^{238}{ }^{8} \mathrm{PuO}_{2}$ fuel in the GPHS. An important material in the GPHS is the thermal insulation to protect the fuel cladding from extremes of temperature at various stages of flight.

The GPHS module is shown in Fig. 1 and is described in detail elsewhere. 1 It contains four fuel pellets encapsulated in vented cladding made of an iridium alloy. Several graphitic materials surround the fuel capsule, including the CBCF thermal insulation. The thermal insulation for each fuel capsule assembly consists of one sleeve and two disks. The

ORNL-DWG 80-18115R

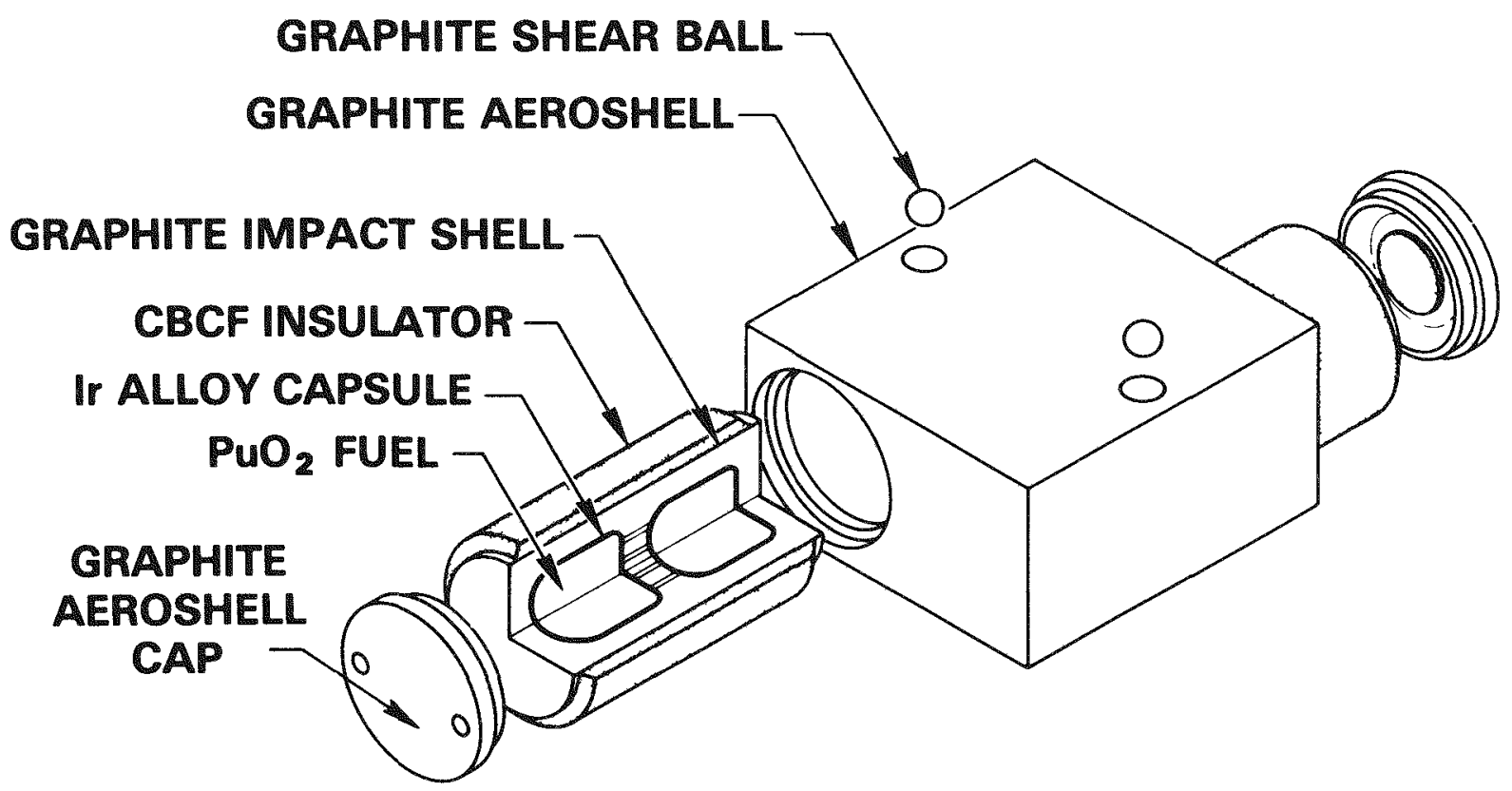

Fig. 1. General Purpose Heat Source module, exploded view. 
disks are bonded to the aeroshell with a high-temperature low-outgassing graphite cement to simplify the final hot cell assembly of the fueled module. During normal GPHS operation, the thermal insulation is under vacuum at $1300^{\circ} \mathrm{C}$ on the hot face and $1000^{\circ} \mathrm{C}$ on the cold face. Under some conditions the outer surface temperatures of the insulation could increase to $2500^{\circ} \mathrm{C}$ or above.

Several stringent requirements must be met by the thermal insulation of the GPHS. Light weight is a necessity to achieve high specific power (watts per kilogram) for the overall system. It should be chemically compatible with other components of the GPHS. The thermal insulation must have long-term stability up to $1350^{\circ} \mathrm{C}$ and must be functional during $2500^{\circ} \mathrm{C}$ transients. Low gas evolution is required because the SiGe thermoelectric elements coated with $\mathrm{Si}_{3} \mathrm{~N}_{4}$ and other components such as fuel claddings are extremely sensitive to oxygen-bearing gaseous species. The insulation material must have sufficient mechanical strength to survive vibrational stresses during launch. Finally, the thermal conductivity must be low to protect the iridium fuel cladding.

Commercial insulations were reviewed for application in the GPHS. Pyrolytic graphite is a good insulator at high temperatures, particularly during transient conditions, but it has higher thermal conductivity and a higher density than $\mathrm{CBCF}$ insulation. Oxide fiber insulations such as Min- ${ }^{*}{ }^{*}$ Zircar, $\dagger$ and Fiberfrax, $\neq$ may react with graphite at operating temperatures and are therefore incompatible with graphite components. The oxide fiber insulations are also limited because of shrinkage and loss of insulation properties at high temperatures. Multifoil insulation ${ }^{* *}$ such as molybdenum foil coated with zirconia has extremely low thermal conductance in vacuum over a wide temperature range but is too dense. The lack of a commercially available thermal insulation that meets the requirements for application in the GPHS led to the development and characterization of a $\mathrm{CBCF}$ insulation.

\footnotetext{
*Min-K, product of Johns-Manville Corp., Denver, Colo. tZircar, product of Zircar Products, Inc., Florida, N.Y. \#Fiberfax, product of Carborundum Co., Niagara Fa11s, N.Y. **Multifoil insulation, product of Thermo Electron Co., Waltham, Mass.
} 
The designation $C B C F$ is a generic name for a class of CBCF insulations initially developed at the Oak Ridge $\mathrm{Y}-12$ Plant. ${ }^{2-4}$ It is fabricated by vacuum molding from water slurries containing chopped carbon fibers and a phenolic resin. One version of $C B C F$ insulation supplied by the Oak Ridge National Laboratory (ORNL) was used in the Apo1lo Lunar Radioisotopic Heater for lunar seismic experiment instrumentation associated with the first lunar landing in 1969 (ref. 5). At ORNL, the basic fabrication technique was refined to eliminate the undesirable large pores and cracks often present in the materials fabricated by the original techniques. Processing was also scaled up to increase the fabrication rate by a factor of 10 . The specific properties of this material were tailored by adjusting material and process variables to meet the system needs. After three iterations, the CBCF material was developed, primarily for general use in radioisotopic thermoelectric generators. The specific properties of $\mathrm{CBCF}$ insulation also made it extremely attractive for application in the GPHS. Rather extensive efforts were then undertaken to fabricate samples and to characterize the thermal, physical, mechanical, and chemical properties of the insulation. Samples and parts were made at ORNL. The comprehensive characterization was carried out at ORNL as well as at a number of other laboratories. The CBCF insulation has low density, compatibility with other graphitic materials in the GPHS, very low thermal conductivity over a wide range of temperature, and the mechanical strength to survive launch vibration tests. These attributes led to the selection of $\mathrm{CBCF}$ insulation for use in the GPHS.

We report here the attributes of $C B C F$ insulation; fabrication refinement and scaleup; engineering data base of the thermophysical, mechanical, and chemical properties; and results of some investigations on the basic mechanisms of the thermal and mechanical performance. We also describe how the work on CBCF characterization and development conducted at ORNL from 1978 to 1980 has contributed to the success of the GPHS program to meet the requirements of both the Galileo and Ulysses Missions. 
FABRICATION AND PROCESS IMPROVEMENT

The fabrication process for CBCF insulation is basically an extension of the earlier development. ${ }^{2}$ However, we have made significant improvements in several critical steps of fabrication to produce parts with fewer defects and better yield. In this section, we describe the basic processing technique and present the process improvement.

\section{FABRICATION}

Figure 2 shows the flowsheet for fabrication of $C B C F$ insulation for the GPHS. Sma11-diameter continuous rayon $\left[\left(\mathrm{C}_{6} \mathrm{O}_{5} \mathrm{H}_{10}\right)_{n}\right]$ filament ${ }^{*}$ was precision chopped to $0.25-\mathrm{mm}$ length with a flock cutter. The rayon filament has a nominal diameter of $10.5 \mu \mathrm{m}$ and a serrated cross section characteristic of regenerated viscose rayon made from wood pulp. Difficulties in achieving reproducibility in properties (including density and strength) in CBCF insulation can of ten be related to the variability in fiber diameter and length, which gives rise to different packing of the fibers and binders during forming. As-received rayon filament can vary several micrometers in diameter from lot to lot. In addition, chopping of the fibers to length is subject to considerable variation. Fibers within a given lot and from lot to lot can vary in average length up to $\pm 0.07 \mathrm{~mm}$. To obtain a uniform batch, a large amount of chopped rayon fibers typically is blended and mixed thoroughly. Consistency of the resin is also important but is less critical than that of the fiber, as discussed later. Chopped rayon fibers were carbonized at $1350^{\circ} \mathrm{C}$ for $3 \mathrm{~h}$ in an inert atmosphere. The carbon yield during pyrolysis of rayon fiber was about 25 wt \% During carbonization, the fibers shrank to an average diameter of about $6.5 \mathrm{~mm}$ and an average length of about $0.15 \mathrm{~mm}$. The carbon fibers were then deagglomerated by passing through a Wiley mill ${ }^{\dagger}$ having two sizing plates with 2- and 0.5-mm-diam holes. The carbon fibers were subsequently blended in a water slurry tank and dried.

\footnotetext{
*Rayon filament, product of American Enka Co., Enka, N.C. ${ }^{\dagger}$ Wiley mill, product of A. H. Thomas Co., Philadelphia, Pa.
} 
ORIL-DWG 83-17236

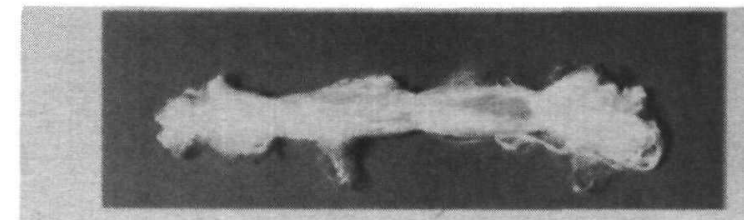

CONTINUOUS RAYON FILAMENT

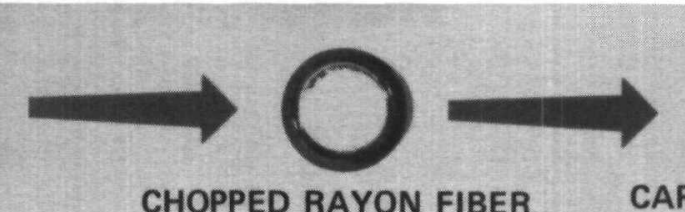

CHOPPED RAYON FIBER
CARBON FIBER

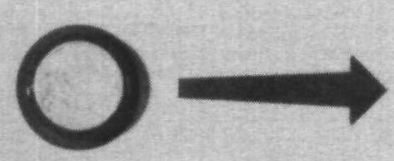

PHENOLIC RESIN

$\begin{array}{llll}\text { MOLDED } & \text { MOLDED } & \text { CYLINDER } & \text { PLATE } \\ \text { CYLINDER } & \text { PLATE } & \text { MANDREL } & \text { MANDREL }\end{array}$
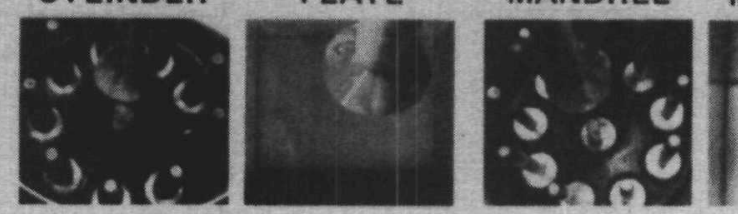

MOLDING (TOP VIEW)

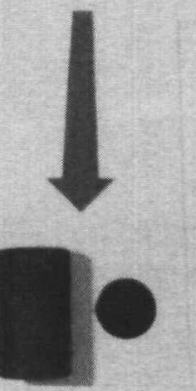

MACHINED PARTS

Fig. 2. Flowsheet for fabrication of carbon-bonded carbon fiber insulation for the General Purpose Heat Source. 
Commercial production of smal1-diameter rayon filament has been essentially eliminated by technical evolution of the tire cord industry. We recently surveyed the rayon fiber industry and could identify only one domestic continuous rayon filament supplier.* This situation prompted an interest in the use of an alternate carbon fiber, namely, polyacrylonitrile $\left[\left(\mathrm{CH}_{2} \mathrm{CHCN}\right)_{n}\right]$ (PAN)-derived carbon fiber. Fabrication of PAN-fiber-based CBCF insulation was undertaken. However, as discussed later, its thermal conductivity was too high, and it had a large temperature dependence, which did not warrant its continued development. 6

A phenolic resint was used as the carbon-bond precursor. It is a $B-s t a g e$, two-step, thermosetting resin consisting of novalak $\left[\left(\mathrm{C}_{6} \mathrm{H}_{5} \mathrm{OHCH}_{2}\right)_{n}\right]$ powder to which about $8 \mathrm{wt} \%$ of hexamethylenetetramine $\left[\left(\mathrm{CH}_{2}\right)_{6} \mathrm{~N}_{4}\right]$ powder is added as an activator for polymerization. The average particle size was $9 \mu \mathrm{m}$, and the carbon yield after pyrolysis was $50 \mathrm{wt} \%$. Typically, the phenolic resin particles were sieved through a 200-mesh screen to remove agglomerates before use.

The carbon fibers were mechanically slurried in water for $30 \mathrm{~min}$. Phenolic resin in a weight ratio of 0.85 to the carbon fibers was added to the water-fiber mix and blended for $20 \mathrm{~min}$ to make a homogeneous distribution. The dilute fiber-resin-water slurry ( $<0.5$ wt $\%$ solids) was vacuum molded into tubular or plate configuration, with the resin particles uniformily dispersed throughout the fibers (Fig. 3). The slurry was fed from the mixing tank to a molding tank containing perforated mandrels with 3.2-mm-diam holes and covered with knitted cotton filter cloth. The solids were deposited on the mandrel while the water flowed through. The slurry was transferred from the mixing tank to the molding tank by removing water in the molding tank at a rate (controlled by the vacuum) such that the molding tank was kept full during molding. The fibers were preferably oriented in planes perpendicular to the thickness direction of the molded form. After molding, excess water in the molded form was drawn

\footnotetext{
*North American Rayon Co., Elizabethton, Tenn.

tDurez 22352 phenolic resin, product of Hooker Chemical Corp., North Tonawanda, N.Y.
} 


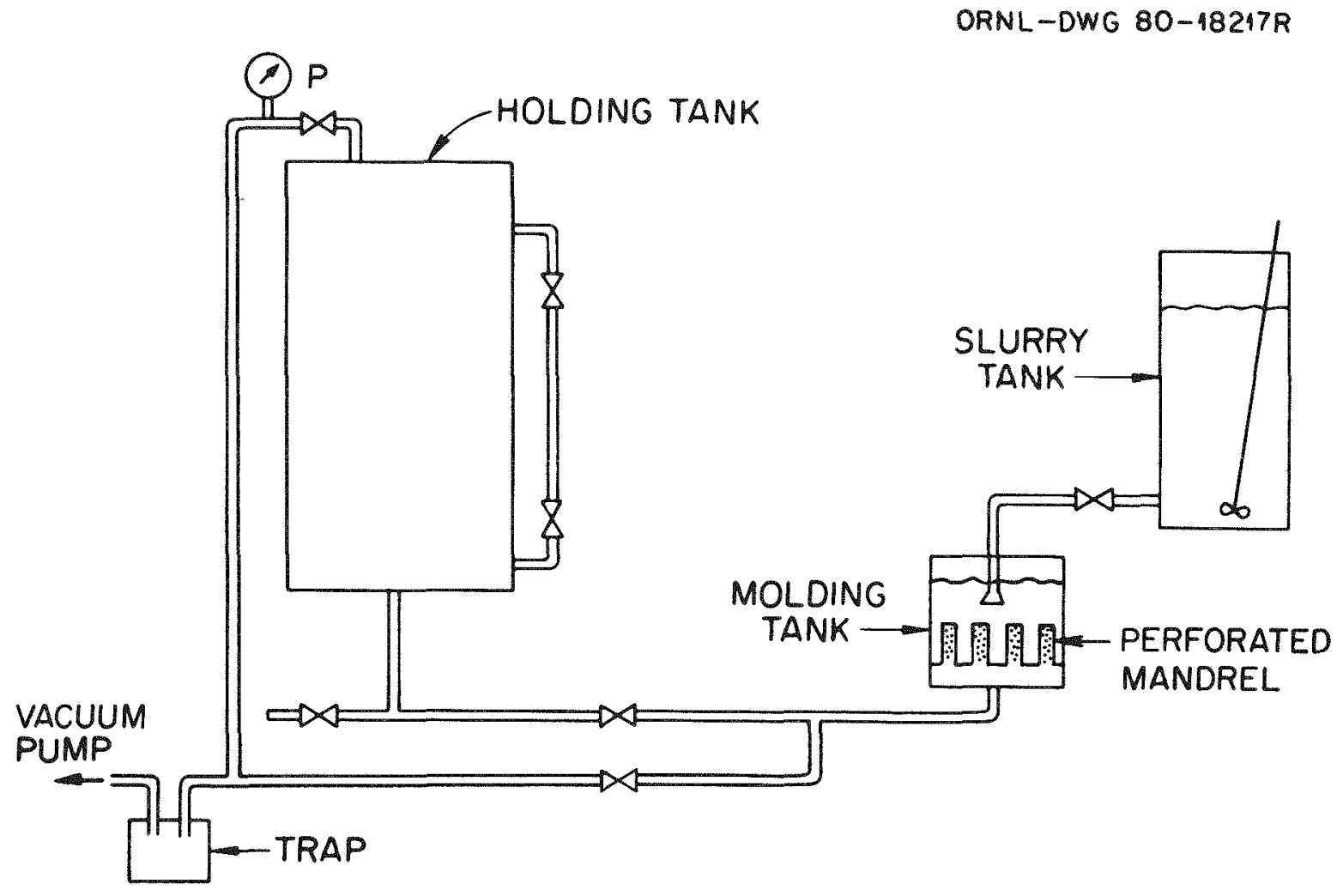

Fig. 3. Schematic of vacuum molding equipment.

off by a vacuum that pulled air through the mold to reduce the water-tosolids ratio to less than 1 . The preferable range of the water-to-solids ratio in dewatered molded forms was empirically determined as 0.7 to 1 to minimize shrinkage during the subsequent drying. Drying of the mold and curing of the resin were accomplished in a forced-draft air dryer. Final carbonization was achieved by heating at a rate of about $300^{\circ} \mathrm{C} / \mathrm{h}$ to $1600^{\circ} \mathrm{C}$ and holding for $3 \mathrm{~h}$ in argon. Carbonization at such a temperature produced parts with acceptable thermal conductivity and ensured dimensional stability of the final machined parts under the subsequent vacuum outgassing at $1500^{\circ} \mathrm{C}$ for $40 \mathrm{~h}$ before assembly of the GPHS module. Carbonized billets were inspected by $\mathrm{X}$-radiography to ensure that the parts were free of large voids, high-density inclusions, and cracks. Core-drilled samples were taken from the carbonized billets for use in determining density, strength, thermal conductivity, and trace impurities. Typically, three characterization samples for each property were prepared 
for $C B C F$ parts produced in every molding run. Machining of the carbonized billets to final parts is a difficult operation. Tolerance to $0.8 \mathrm{~mm}$ can be attained by using single-point tooling in conjunction with appropriate fixturing for support of the fragile billet. A vacuum fixture was used for CBCF disks, but, for CBCF sleeves, the pressure for holding the billet had to be carefully controlled to avoid permanent deformation or damage to the part. Final machined parts were visually and dimensionally inspected and then examined by $\mathrm{X}$-radiography before shipment.

\section{PROCESS IMPROVEMENT}

As mentioned earlier, the average length and length distribution of carbon fibers greatly affect the properties of the fabricated parts. For example, two batches of carbon fibers with somewhat different average fiber length and length distribution resulted in final parts differing in density by about $12 \%$. As may be inferred from Table 1 (total number of fibers counted was over 2000), the average fiber lengths of batches $A$ and $B$ are about 0.15 and $0.13 \mathrm{~mm}$, respectively. The fiber length distributions in both cases are single mode, but batch $B$ is more densely populated in the shorter side of the distribution. The densities of CBCF-type insulation fabricated from batches $A$ and $B$ with the same formulation and processing variables are 0.25 and $0.28 \mathrm{Mg} / \mathrm{m}^{3}$, respectively. This example illustrates that fiber length must be carefully monitored to maintain manufacturing control. Fiber length and distribution were determined with ease by computer-aided microscopic image analysis, but meaningful sampling

Table 1. Density and carbon fiber length distribution for a carbon-bonded carbon fiber insulation made from two different batches of fiber

\begin{tabular}{cccccccccc}
\hline $\begin{array}{l}\text { Carbon } \\
\text { fiber } \\
\text { batch }\end{array}$ & $\begin{array}{c}\text { Densfty } \\
\left(\mathrm{Mg} / \mathrm{m}^{3}\right)\end{array}$ & 550 & $51-100$ & $101-150$ & $151-200$ & $201-250$ & $251-300$ & $301-350$ & $>350$ \\
\cline { 3 - 10 } & 0.25 & 3 & 9 & 25 & 49 & 8 & 3 & 3 & 1 \\
A & 0.28 & 14 & 23 & 30 & 24 & 7 & 1 & 1 & 0.5 \\
\hline
\end{tabular}


was difficult. Separating fibers of different lengths with a conventional vibratory shape separator was ineffective, primarily because of the high aspect ratios of the fibers. Further development of techniques is required for meaningful sampling and length separation of carbon fibers. The settling of short fibers during storage could be significant. The CBCF parts made of fibers from the bottom of the storage drum could be appreciably denser than those parts consisting of fibers from the top of the storage drum. Further work is needed to define an optimal storage condition and to study the segregation effects.

Efforts were undertaken to solve the problem of excessively large pores commonly observed in CBCF parts made by the earlier process. ${ }^{2-4}$ Such pores are thought to be detrimental to strength and thermal conductivity of the insulation. Radiography was used extensively in examining the parts for defects. Numerous pores up to $2 \mathrm{~mm}$ in diameter were observed in carbonized parts. Radiographic examination of as-cured and uncured parts indicated numerous pores, especially in the top portion of the green (uncured) parts. Therefore, the presence of large pores was not related to carbonization but was due to molding and/or slurry preparation. The molding and slurry preparation were then critically reviewed. Large agglomerates of resin particles were thought to be one possible source of the large pores but were ruled out after parts made with sieved resin particles still showed large pores.

The fact that most of the pores were in the top portion of the tubes suggests that increasing the water level in the molding tank may be helpful in eliminating the pores. Air bubbles produced during slurry preparation could also result in the pores. Consequently, the following process modifications were made: (1) increasing the water level in the molding tank to reduce the aeration due to the splashdown of the fiber-resin-water slurry from the slurry tank to the molding tank and (2) stopping the agitation in the slurry tank for $3 \mathrm{~min}$ before molding to let air bubbles escape while maintaining a reasonably homogeneous slurry. Calculation of the settling of fibers or resin particles in the water slurry by Stokes' law 


$$
V=2 d^{2}\left(\rho_{p}-\rho \eta\right) g / 9 \eta
$$

where

$$
\begin{aligned}
V= & \text { terminal speed in } \mathrm{cm} / \mathrm{s}, \\
d= & \text { resin particle diameter }(9 \mathrm{~mm}) \text { or fiber's equivalent size } \\
& (30 \mathrm{~mm}) \text { in } \mathrm{cm}, \\
\rho_{p}= & \text { density of the resin particle }\left(1.2 \mathrm{Mg} / \mathrm{m}^{3}\right) \text { or of the fiber } \\
& \left(1.6 \mathrm{Mg} / \mathrm{m}^{3}\right), \\
\rho_{l}= & \text { density of the liquid }\left(1 \mathrm{Mg} / \mathrm{m}^{3}\right), \\
g= & \text { gravity constant }\left(980 \mathrm{~cm} / \mathrm{s}^{2}\right), \\
\eta= & \text { viscosity of water }\left(1 \mathrm{mPa}^{\circ} \mathrm{s}\right),
\end{aligned}
$$

indicated a terminal speed of less than $0.05 \mathrm{~mm} / \mathrm{s}$ for both fiber and resin. Therefore, stopping agitation for $3 \mathrm{~min}$ to allow all bubbles to escape would not cause significant nonuniformity in the slurry.

The above two process modifications greatly reduced both the size and population of the pores in $C B C F$ parts. Typically, pores larger than $1 \mathrm{~mm}$ were essentially eliminated. The use of a wetting agent to eliminate the air bubbles in the slurry tank was considered but not pursued because the sulfur or phosphorus in most available wetting agents could contaminate CBCF parts and because elther sulfur or phosphorus could seriously degrade the impact ductility of the iridium fuel capsule in the GPHS. In addition, high-density inclusions revealed by $\mathrm{X}$-radiography and identified as an iron compound by electron microprobe analysis were essentially eliminated by filtering the water and carefully cleaning molding equipment.

We have established a multiple-mandrel molding facility that can form nine CBCF tubular forms per molding run (Fig. 2). The nine perforated mandrels are equally spaced on a $0.5-\mathrm{m}$-diam circle in the molding tank. The density variation from part to part in a multiple-mandrel run was generally within $\pm 5 \%$. This variation was much smaller than the density variation (up to about 30\%) from multimandrel run to multimandre1 run within one batch of fiber. The development and installation of the multiple molding facility increased the speed of fabrication by almost a 
factor of 10, and improved consistency from part to part on each run was achieved. In principle, the multimandrel molding system can be scaled up even further by use of more mandrels if the need is justified.

Cracking in the final carbonized $C B C F$ tubes was at one time a serious problem. It typically occurred as a longitudinal crack across the thickness and paralle1 to the axis of the CBCF tube. The pattern of the cracks suggested some diametral tensile stresses generated in processing. The heatup rate of carbonization was varied and was found to be unrelated to the cracking problem. Drying and curing steps were then critically reviewed. Residual stresses generated hy shrinkage anisotropy (radial to axial) of the green forms in the drying and curing stages could cause the cracking. Such residual stresses are very difficult to determine with conventional $X$-ray diffraction line-broadening analysis because of the amorphous state of the carbon fiber and bond. Curing of phenolic resin generally occurs at temperatures from 80 to $130^{\circ} \mathrm{C}$. The polymerization or curing reaction is exothermic and releases $\mathrm{NH}_{3}$ and hydrogen. ${ }^{7}$ The curing reaction is further complicated by the evolution of water in the green or as-molded part. Drying and curing at a slower rate accomplished in four steps $\left(50^{\circ} \mathrm{C}\right.$ for $16 \mathrm{~h}, 80^{\circ} \mathrm{C}$ for $3 \mathrm{~h}, 100^{\circ} \mathrm{C}$ for $3 \mathrm{~h}$, and $130^{\circ} \mathrm{C}$ for $16 \mathrm{~h}$ ) instead of the old single-step operation $\left(100^{\circ} \mathrm{C}\right.$ for $\left.48 \mathrm{~h}\right)$ significantly reduced the cracking. The residual stresses conceivably can increase with increasing diameter and thickness of the tubular body. Analytical modeling of the residual stresses, experimental analysis of the off-gases, and correlation with heatup rate are highly desirable.

A low-voltage $X$-radiographic technique was employed to examine the final parts nondestructive1y. Instead of the customary $22-k V x-r a y$ source, this low-voltage radiography uses an $8-\mathrm{kV}$ source with a helium chamber between the target and bare film to improve attenuation. ${ }^{8}$ The technique proved to be very powerful in revealing internal pores measured to size of $1 \mathrm{~mm}$, high-density inclusions, and even minor surface scratches not visible under a $10 \times$ magnification. Note that $C B C F$ has a nominal density of $0.21 \mathrm{Mg} / \mathrm{m}^{3}$, so even the resin carbon bond will show up radiographically as a high-density inclusion when compared with the density 
of the part. With the process improvement discussed above in place, CBCF parts typically are essentially free of any cracks and of high-density inclusions and pores larger than $1 \mathrm{~mm}$.

\section{CHARACTERIZATION AND PROPERTIES}

During the development of $\mathrm{CBCF}$ insulation, properties including outgassing levels, impurity content, density, strength, and thermal conductivity were characterized. The properties reported in this section were all on outgassed samples unless otherwise noted.

\section{OUTGASSING}

Previous experience with the detrimental effects of water vapor released from graphite and fibrous oxide insulations on silicon-germanium thermoelectric elements and fuel cladding in the RTGs planned for the 1972 Pioneer Mission led to stringent outgassing requirements for all thermal insulations in all RTGs (ref. 9). We investigated the outgassing behavior of $\mathrm{CBCF}$ insulation and established a standard outgassing procedure based on the data obtained with a high-temperature vacuum microbalance equipped with a residual gas analyzer. Experimental details documented elsewhere 0 are not repeated here. The $C B C F$ specimens were first outgassed at high temperatures representing the preassembly vacuum heat treatment of the insulation to be used in the RTG. The outgassed specimens were then exposed to argon at room temperature for $100 \mathrm{~h}$ to simulate storage before actual generator assembly and startup. Samples were then slowly heated in vacuum to $1350^{\circ} \mathrm{C}$ (secondary outgassing) for $100 \mathrm{~h}$ to simulate generator startup and normal operation and were finally heated to $1800^{\circ} \mathrm{C}$ for $5 \mathrm{~min}$ to obtain the total amount of volatile species in the specimens. Outgassing at $1500^{\circ} \mathrm{C}$ for $40 \mathrm{~h}$ under $7 \mathrm{mPa}(5.0 \mathrm{E}-5$ torr) was established as the standard outgassing procedure. Specimens typically lost a total of $0.6 \%$ in weight, with essentially all the weight loss completed in the first $30 \mathrm{~h}$ of the $40-\mathrm{h}$ outgassing. Major off-gas species were $\mathrm{CO}, \mathrm{CO}_{2}$, $\mathrm{H}_{2} \mathrm{O}, \mathrm{O}_{2}, \mathrm{~N}_{2}$, and Ar. Specimens so outgassed showed only a very small 
amount $(0.004 \%)$ of readsorption of gases during exposure to argon, and that was all released as $\mathrm{CO}, \mathrm{CO}_{2}$, and Ar during the secondary outgassing, simulating the RTG startup and operation. During the final $1800^{\circ} \mathrm{C} 5-\mathrm{min}$ transient, specimens typically released $\mathrm{CO}$ and $\mathrm{CO}_{2}$, with a total weight loss of $0.02 \%$. This was comparable to other graphitic materials such as POCO* graphite and was considered acceptable. Table 2 1ists the outgassing data. Outgassing at temperatures higher than $1500^{\circ} \mathrm{C}$ would remove more of the volatile species but might also result in some graphitization and increased thermal conductivity in carbon fibers and binders. Typically, the graphitization extent in samples outgassed at $1500^{\circ} \mathrm{C}$ for $40 \mathrm{~h}$ was too small to be detected by routine $\mathrm{X}$-ray diffraction. The thermal conductivity of outgassed specimens showed no increase over that of the $\mathrm{CBCF}$ before outgassing.

DENSITY

Bulk density was obtained by measuring the weight and dimensions of outgassed samples. Figure 4 shows the density data collected for $\mathrm{CBCF}$

*Poco graphite, products of POCO Graphite, Inc., Decatur, Tex.

Table 2. Carbon-bonded carbon fiber outgassing experiment results

\begin{tabular}{lcc}
\hline \multicolumn{1}{c}{ Outgassing step } & \multicolumn{1}{c}{ Weight loss or gain (\%) } \\
\cline { 2 - 3 } & Initial weight & Total loss \\
\hline $\begin{array}{l}\text { Primary outgassing }\left(1500^{\circ} \mathrm{C} \text { for } 40 \mathrm{~h} \text { under }\right. \\
7 \mathrm{mPa} \text { vacuum) }\end{array}$ & -0.57 & 95.0 \\
$\begin{array}{l}\text { Exposure to argon at room temperature for } \\
100 \mathrm{~h}\end{array}$ & +0.004 & 0.8 \\
$\begin{array}{l}\text { Secondary outgassing to } 1350^{\circ} \mathrm{C} \text { and held at } \\
1350^{\circ} \mathrm{C} \text { for } 100 \mathrm{~h} \text { under vacuum }\end{array}$ & -0.004 & \\
$1800^{\circ} \mathrm{C}$ ramp & -0.02 & 4.2 \\
\hline
\end{tabular}




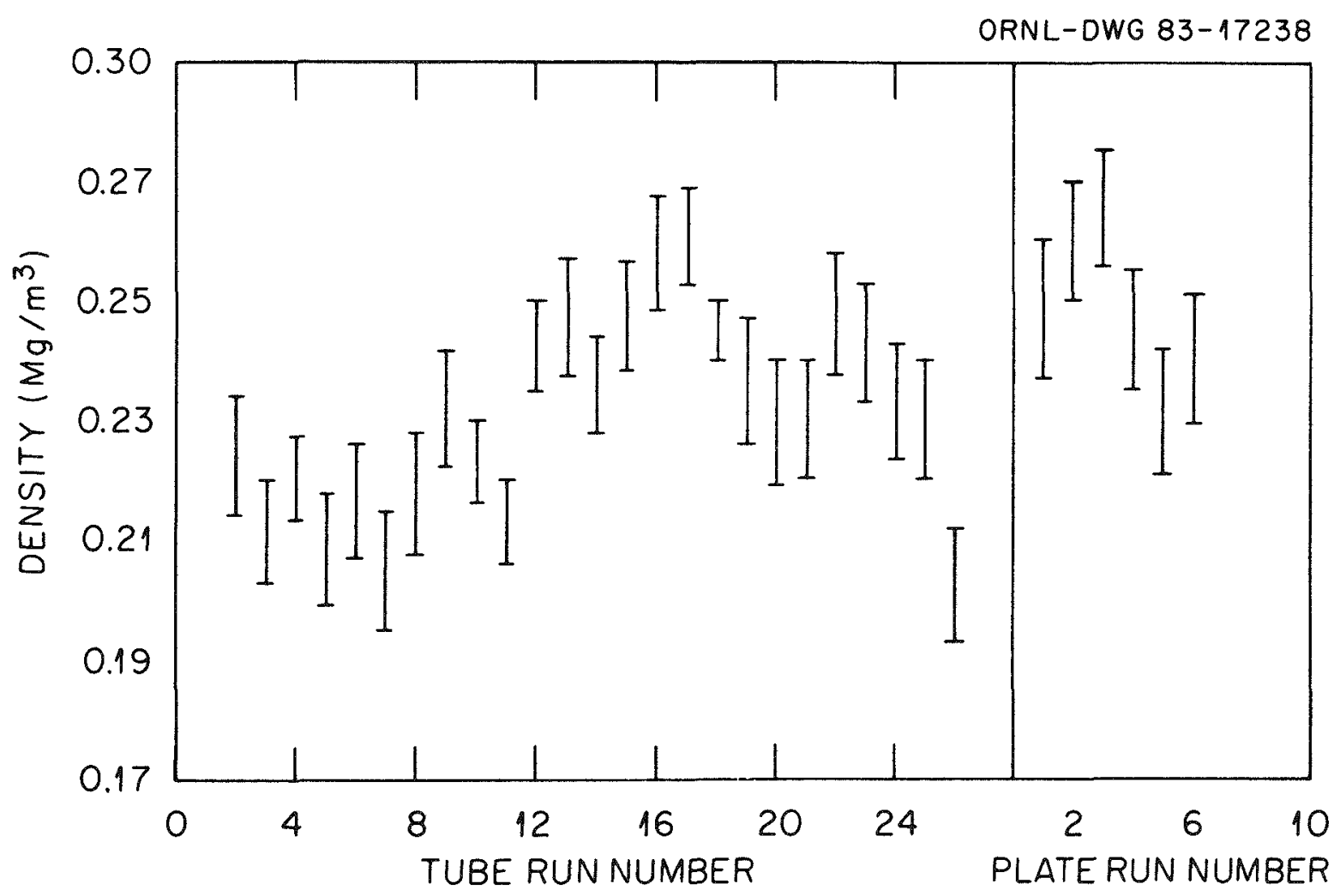

Fig. 4. Density of samples machined from carbon-bonded carbon fiber tubes and plates made with multimandrel molding facility.

parts made in 26 multiple molding runs for tubes and in 6 runs for plates. At $95 \%$ probability, the density ranged from 0.19 to $0.27 \mathrm{Mg} / \mathrm{m}^{3}$ for a $95 \%$ confidence level for the lot mean. As mentioned before, density depends primarily on the packing of fibers, which, in turn, hinges on fiber length and length distribution.

According to the analytical model of fiber random packing by Milewski, the nominal length-to-diameter $(L: D)$ ratio (23) of the carbon fiber in $\mathrm{CBCF}$ results in a bulk volume of $7 V_{f}$, where $V_{f}$ is the fiber volume, for packing of fibers only. 11 The carbon binder in CBCF is derived from phenolic resin and is about $7 \mu \mathrm{m}$ in particle size. Because loose packing of the resin produces a bulk volume 4 times that of the resin volume, it is reasonable to assume that the volume of random packing 
of the carbon binder is 4 times the carbon binder volume $V_{B}$. Combined packing of the carbon fibers (with an $L: D$ ratio of 23 ) and the binder [with a ratio of binder diameter $(6.5 \mu \mathrm{m})$ to fiber diameter $(6.5 \mu \mathrm{m})$ of 1 ] introduces an additional void volume that is $54 \%$ of the sum of the bulk volumes of packings for fibers alone and for binder alone, according to Milewski's analysis.11 Thus, the total bulk volume $V$ of randomly packed fibers and binder is

$$
V=1.54\left(7 V_{f}+4 V_{B}\right)
$$

Considering CBCF in which the $V_{B}$ is $40 \%$ of the $V_{f}, E q \cdot(2)$ becomes

$$
V=1.54\left(7 V_{f}+1.6 V_{f}\right)
$$

Equation (3) shows that the bulk volume is controlled to a much greater extent by the fiber than it is by the binder. The bulk density $\rho$ is then

$$
\rho=\left(W_{f}+W_{B}\right) / 13.2 V_{f}
$$

where $W_{f}$ is the fiber mass and $W_{B}$ the binder mass. Since $W_{B}=0.4 W_{f}$ in $\mathrm{CBCF}$ and the density of the carbon fiber $\left(\rho_{f}=W_{f} / V_{f}\right)$ or carbon binder is $1.6 \mathrm{Mg} / \mathrm{m}^{3}$, Eq. (4) leads to a bulk density of $0.17 \mathrm{Mg} / \mathrm{m}^{3}$ for random packing of carbon fibers and binders in CBCF.

In $C B C F$, the packing of carbon fibers is oriented with most of the fibers aligned parallel to the mandrel surface because of vacuum molding in fabricaition. It is therefore not surprising that the measured density $\left(0.19\right.$ to $\left.0.27 \mathrm{Mg} / \mathrm{m}^{3}\right)$ is always greater than that $\left(0.17 \mathrm{Mg} / \mathrm{m}^{3}\right)$ calculated for random packing. It should also be noted that fiber length distribution, which could affect density, was not considered in the modeling.

The above analysis shows that $\mathrm{CBCF}$ density is controlled by the fiber length-to-diameter ratio, the carbon binder-to-fiber diameter ratio, the binder content $\left(W_{B}: W_{f}\right.$ ratio), the fiber density $\left(W_{f}: V_{f}\right)$, and the degree of preferred orientation. The amount of preferred orientation depends on the vacuum (pressure differential) used in the molding process; on the drying and curing rate; and, to a great extent, on the fiber length and length distribution. During drying and curing, the thermosetting resin shrinks about $20 \%$ and migrates somewhat. The heating rate and temperature of 
drying and curing can affect the amounts of shrinkage and migration and, therefore, the final density.

\section{IMPURITIES}

Samples were subjected to chemical analyses, including ash analysis and spark source mass spectroscopic chemical analysis for trace impurities. The CBCF consistently showed a total ash content of less than $3000 \mathrm{ppm}$, with the following major impurities: Si, less than $300 \mathrm{ppm}$; Ca, $T 1, V, F e$, and S, less than $200 \mathrm{ppm}$; and all others, less than $100 \mathrm{ppm}$. Such high purity is required for use in the GPHS. These major impurities seem to be strongly bonded to carbon atoms because none of them were detected in the off-gas during the secondary outgassing simulating the generator startup and operation and the $1800^{\circ} \mathrm{C}$ ramp. The source of sulfur is believed to be rayon fiber, which is typically synthesized from wood pulp and spun to fibers in an $\mathrm{H}_{2} \mathrm{SO}_{4}$ bath. Silicon and iron might have been introduced during chopping and wiley milling. Other impurities including $\mathrm{Ca}, \mathrm{TI}$, and $\mathrm{V}$ are often found in two-step phenolic resins, whose production involves the use of a small amount of lime and talc during pulverizing.

MECHANICAL PROPERTIES

Compressive strengths of CBCF samples (disks core-drilled from the cylinders or plates) were measured at a crosshead speed of $8.5 \mu \mathrm{m} / \mathrm{s}$. In the direction perpendicular to the fiber array, the stress-versusdeflection curve is typically linear to about $4 \%$ strain. From $4 \%$ strain to about $40 \%$ strain, the stress-strain curve is generally concave downward. At about $40 \%$ strain, samples generally crushed. Apparently, elastic deformation occurs up to $4 \%$ strain, after which structural degradation occurs. To characterize the strength of $\mathrm{CBCF}$, the stress at $5 \%$ strain directly read off the curve of stress versus deflection was defined as the compressive strength. Over 100 samples from CBCF tubes fabricated in 25 multimandrel molding runs and plates made in seven molding runs were 
tested. The compressive strength in the thickness direction varied from $0.52 \mathrm{MPa}$ (76 psi) to $1.12 \mathrm{MPa}$ (160 psi), and sample densities ranged from 0.19 to $0.25 \mathrm{Mg} / \mathrm{m}^{3}$. Data are shown in Fig. 5. The compressive strength $\sigma_{f}$ increases with increasing density. A least-squares fit yields the following relationship: $\sigma_{f}(\mathrm{MPa})=0.33+2.74 \mathrm{p}\left(\mathrm{Mg} / \mathrm{m}^{3}\right)$. This is believed to be caused by increased cross linking among fibers associated with increasing density. Literature on the mechanical behavior of porous fiber insulation is scarce. Note that the scattering of the data points in a plot of compressive strength against density was rather large (standard deviation 20\%). The lower limit instead of the average of the compressive strength of $\mathrm{CBCF}$ was more significant from the viewpoint of launch vibration surviva1. The CBCF parts with densities $\left(0.19-0.20 \mathrm{Mg} / \mathrm{m}^{3}\right)$ and strengths $(0.52-0.70 \mathrm{MPa})$ in the lower end of the statistical range were subjected to a series of vibration tests in a mock-up GPHS module

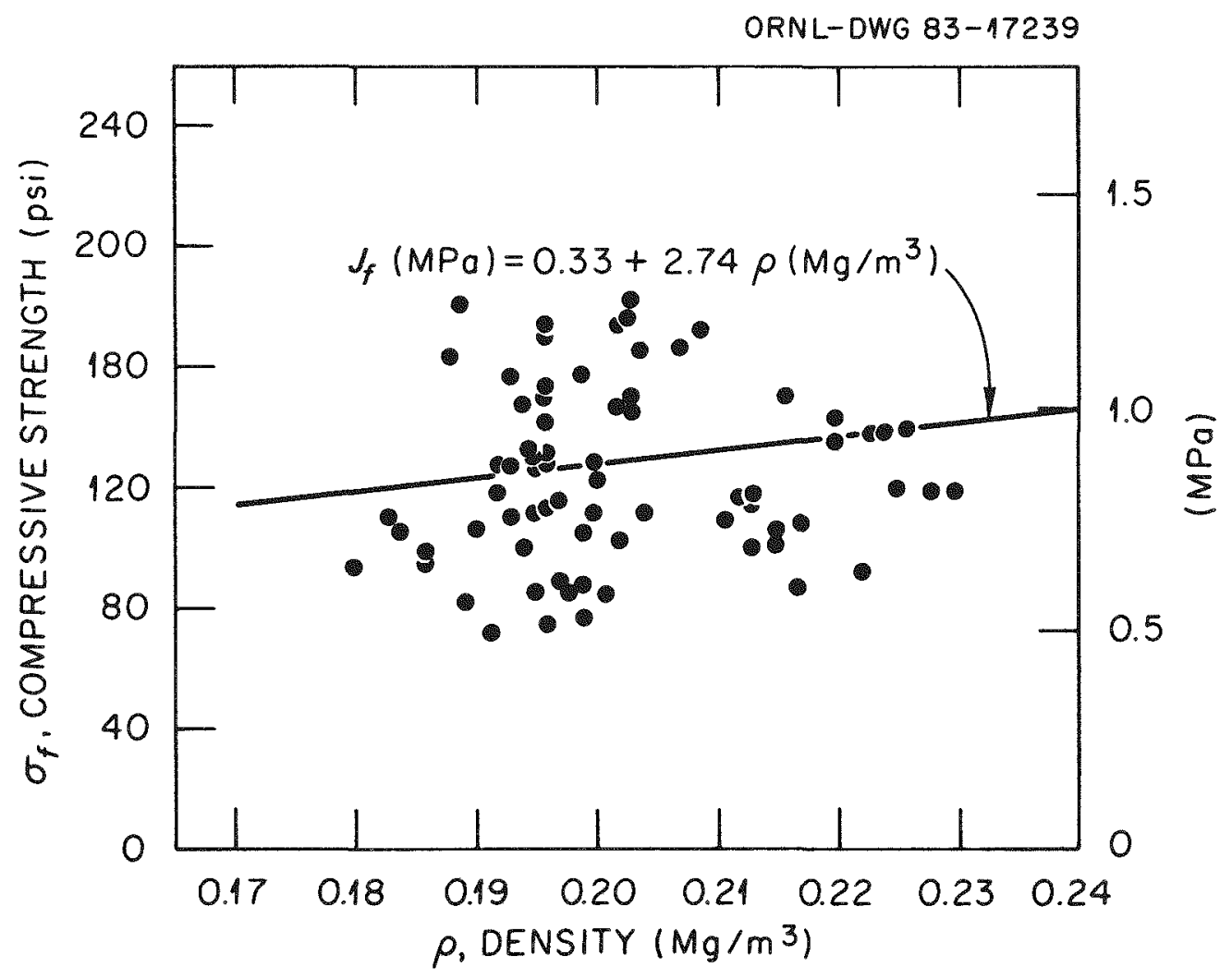

Fig. 5. Compressive strength versus density of carbon-bonded carbon $f i b e r$ in the thickness direction at room temperature. Least-squares fit: $\sigma_{f}(\mathrm{MPa})+2.74 \rho\left(\mathrm{Mg} / \mathrm{m}^{3}\right)-0.33$. 
simulating launch conditions. The vibration tests consisted of 3-min random vibrations in three directions at the flight, qualification, and twice the qualification levels as well as transient vibrations with a $40-\mathrm{g}$ peak load. The CBCF parts showed negligible dimensional or weight changes after the tests and were found to be intact on X-radiographic examination. 12 Therefore, the minimum compressive strength $(0.51 \mathrm{MPa})$ corresponding to these $C B C F$ parts was used as one of the acceptance criteria. Elastic modulus in the thickness direction of $\mathrm{CBCF}$ calculated from the stressversus-strain curves ranges from 11 to $28 \mathrm{MPa}$. The relatively low elastic modulus of CBCF makes it extremely resistant to thermal shock. Both the elastic modulus and compressive strength of $\mathrm{CBCF}$ in the direction parallel to the fiber array are typically about 4 times those in the direction perpendicular to the fiber array. This anisotropy results from the preferred orientation of fibers in $\mathrm{CBCF}$ as shown in Figs. 6 and 7. The elastic modulus and compressive strength at high temperatures (to $1200^{\circ} \mathrm{C}$ ) in vacuum or inert gases were actually slightly higher than those at room temperature. Long-term aging $\left(1350^{\circ} \mathrm{C}\right.$ for $1000 \mathrm{~h}$ under vacuum) had no effect on the strength.

Cyclic compression tests of CBCF samples were conducted in the molding direction at room temperature. The results are shown in Table 3. Note that $\mathrm{CBCF}$ has a permanent set of less than $12 \%$ and no additional reduction in thickness after 40,000 constant-10ad [0.69 $\mathrm{MPa}$ (1000 psi)] cyclic loadings.

In situ observation of $\mathrm{CBCF}$ under a scanning electron microscope (SEM) aided with a videotape showed some interesting features of microstructural changes under cyclic loading. Two important aspects of microstructural changes assoclated with cyclic loading are as follows.

1. The CBCF initially responds to compression by rotation or realignment of the $C B C F$ network with a limited amount of fiber breakage and fully recovers to its original thickness on the release of the load for strains of less than $4 \%$. The fiber typically breaks in what appears to be a bending mode. As the strain exceeds the $4 \%$ "elastic limit," more fibers start to break and, finally, when the strain reaches 40 or $50 \%$, massive breakage of fibers occurs. Surprisingly, fracture of carbon binders was not observed in any stage. 
ORRL-DWG 79-8294
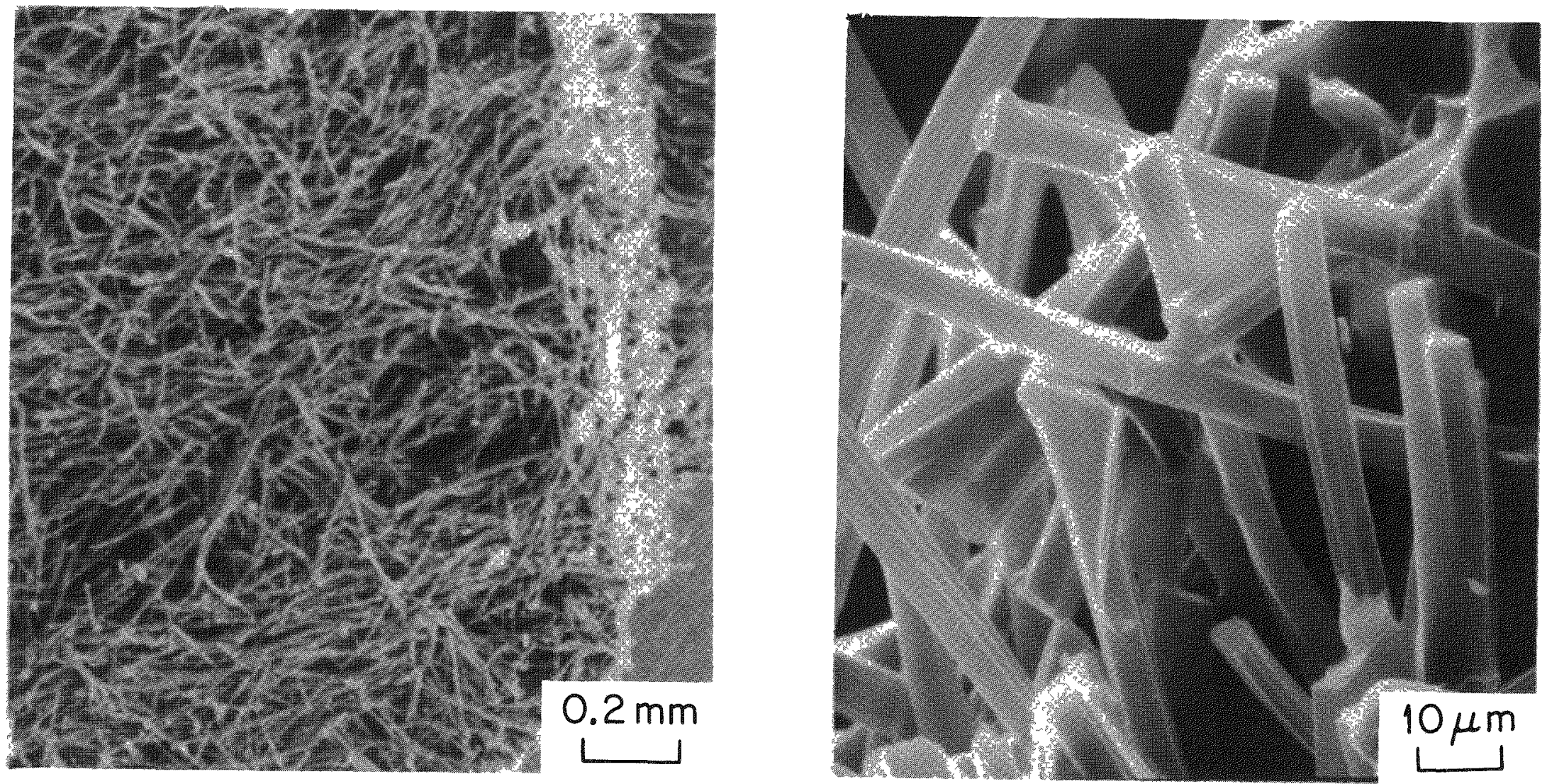

Fig. 6. Scanning electron micrographs of carbon-bonded carbon fiber. 
$\$ 193760$

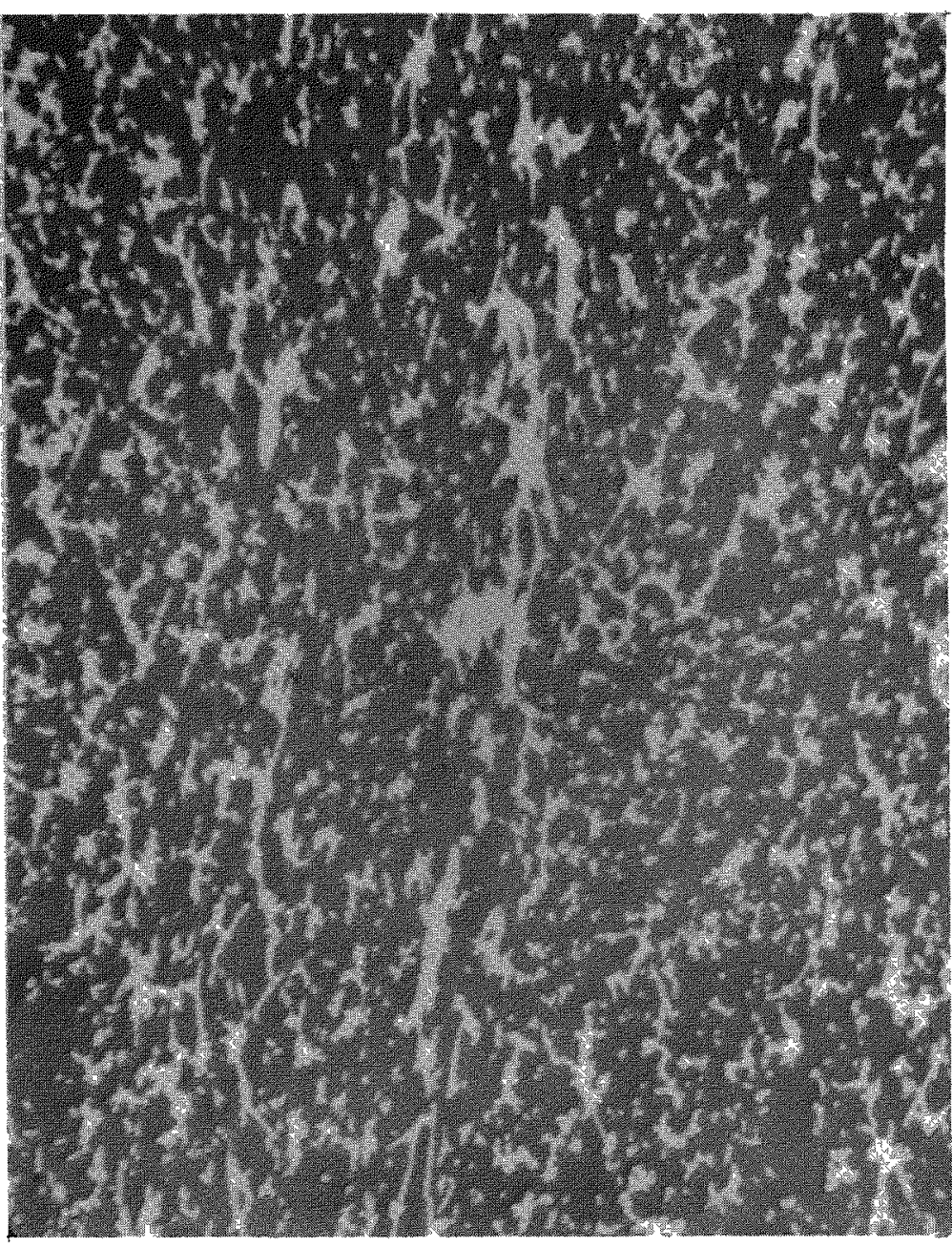

(b)

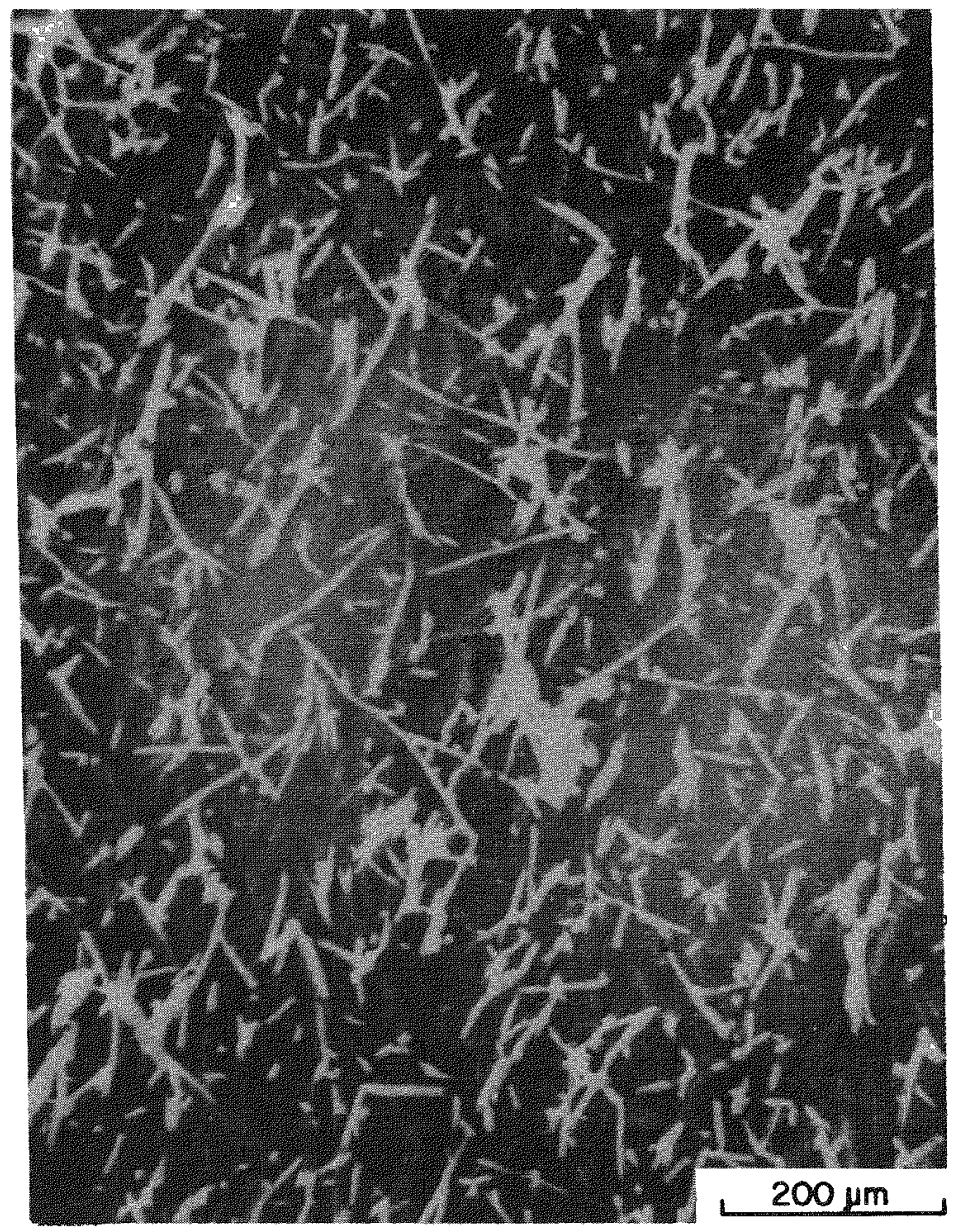

Fig. 7. Micrographs of polished sections of carbon-bonded carbon flber. (a) View perpendicular to the molding direction. (b) View parallel to the molding direction. 
Table 3. Results of cyclic loading tests ( $75 \mathrm{~Hz}$, constant load) of carbon-bonded carbon fiber (CBCF) at room temperature

\begin{tabular}{|c|c|c|c|c|c|c|c|c|c|c|}
\hline \multirow{3}{*}{$10^{3}$ Cycles } & \multicolumn{10}{|c|}{ Thickness (m) after cycling at each stress in MPa (psi) } \\
\hline & \multicolumn{8}{|c|}{$\rho=0.27 \mathrm{Mg} / \mathrm{m}^{3}$} & \multicolumn{2}{|c|}{$\rho=0.20 \mathrm{Mg} / \mathrm{m}^{3}$} \\
\hline & $\begin{array}{l}0.34 \\
(50)\end{array}$ & $\begin{array}{l}0.52 \\
(75)\end{array}$ & $\begin{array}{r}0.69 \\
(100)\end{array}$ & $\begin{array}{r}0.86 \\
(125)\end{array}$ & $\begin{array}{r}1.03 \\
(150)\end{array}$ & $\begin{array}{l}1.21 \\
(175)\end{array}$ & $\begin{array}{l}1.38 \\
(200)\end{array}$ & $\begin{array}{r}1.72 \\
(250)\end{array}$ & $\begin{array}{l}0.34 \\
(50)\end{array}$ & $\begin{array}{r}0.69 \\
(100)\end{array}$ \\
\hline 0 & 2.098 & 2.202 & 2.002 & 2.179 & 1.953 & 2.047 & 2.037 & 2.080 & 1.943 & 2.116 \\
\hline 4 & 2.070 & 2.197 & 1.989 & & 1.859 & 2.029 & 2.017 & 2.029 & 1.930 & 2.045 \\
\hline 10 & 2.060 & 2.192 & 1.984 & 2.118 & 1.842 & 2.012 & 1.989 & 1.892 & & 2.017 \\
\hline 14 & & 2.192 & 1.979 & 2.096 & 1.834 & 1.999 & 1.963 & 1.758 & 1.905 & 2.007 \\
\hline 20 & 2.057 & & 1.979 & 2.088 & 1.829 & 1.974 & 1.956 & 1.664 & 1.905 & 1.984 \\
\hline 30 & & 2.184 & 1.976 & 2.068 & 1.801 & 1.951 & 1.951 & 1.618 & 1.905 & 1.969 \\
\hline 40 & & 2.184 & 1.976 & 2.052 & 1.791 & 1.920 & 1.930 & 1.575 & & 1.880 \\
\hline 50 & 2.057 & & & 2.040 & 1.788 & 1.882 & 1.905 & 1.501 & & 1.880 \\
\hline 60 & & 2.182 & 1.976 & 2.032 & 1.781 & 1.849 & 1.892 & 1.443 & & \\
\hline 80 & & 2.179 & & 2.032 & & 1.791 & 1.839 & 1.280 & & \\
\hline 100 & 2.057 & & 1.976 & 2.032 & 1.770 & 1.765 & 1.788 & 1.074 & & \\
\hline 150 & & & & & 1.753 & 1.740 & 1.555 & $a$ & & \\
\hline 200 & & & & & 1.742 & 1.732 & 1.415 & & & \\
\hline 300 & & & & & 1.732 & 1.704 & $a$ & & & \\
\hline Net change, \% & 2 & 1 & 1 & 7 & 11 & 17 & $30^{\alpha}$ & $40 a$ & 2 & 11 \\
\hline
\end{tabular}

a Powdered.

2. The amount of local deformation of fiber network rotation, shear, compression, and so forth is not uniform throughout the thickness. It decreases from a maximum amount of local compression at the surface to a very sma11 amount of local compression at the center of the thickness. This implies more microstructural damage at the surface than in the bulk material in compression-loaded CBCF.

The in situ SEM observation of compression loading of CBCF elucidated its mechanical behavior and pointed out the directions for further improvement of the mechanical properties of $\mathrm{CBCF}$-type materials. The use 
of stronger fibers such as PAN carbon fiber with elastic modulus and tensile strength higher than that of rayon carbon fiber could conceivably improve the compressive strength of CBCF-type insulation. Unfortunately, carbon fibers with higher strength typically have higher thermal conductivity, which would cause a substantial increase in the thermal conductivity of the fibrous insulation. For example, one type of PAN-carbonfiber-base CBCF insulation with a density of $0.29 \mathrm{Mg} / \mathrm{m}^{3}$ has thermal conductivity 2 to 3 times that of a rayon-carbon-fiber-base CBCF insulation (density, $0.26 \mathrm{Mg} / \mathrm{m}^{3}$ ) in vacuum from 25 to $1000^{\circ} \mathrm{C}$ (ref. 6). The joint between the carbon binder and PAN carbon fiber also appears to be less perfect than that of the rayon carbon fiber. This can be explained by the serrated surface of the rayon carbon fiber in contrast to the smooth PAN carbon fiber.

Because of the discovery of fracture in fiber and not in binder, it becomes possible to formulate a simple model of the strength as a function of density. Figure 8 shows the basic assumption that the fibers are in an orderly arrangement, with fibers lying in planes perpendicular to the molding direction. Carbon binder is neglected in this simple model because fracture occurs in fibers and not in binders. In adjacent planes, the fibers are oriented at right angles. More rigorous modeling would include considerations of nonparallelism of planes of fiber arrays and random orientation of fibers on a given plane of fiber array. Simple geometric consideration (Fig. 8) shows that the nominal distance $Z$ between fibers in a given fiber plane is

$$
Z=\pi d / 4(1-P),
$$

where $d$ is the fiber diameter and $P$ the fractional porosity. Equation (5) can be expressed in terms of bulk density $\rho$ :

$$
Z=\pi d \rho_{f} / 4 \rho \text {, }
$$

where $\rho_{f}$ is the fiber density. For a $C B C F$ under compression, fiber $C$ (Fig. 8) can be viewed as under bending, with fibers $A, B$, and $D$ acting as loading pins. Therefore, the critical bend stress $\sigma_{C}$ in fiber $C$ is

$$
\sigma_{c}=\sigma_{f} z^{3} / \pi r^{3}
$$

where $\sigma_{f}$ is the apparent compressive stress that fractures fiber $C$. 
ORNL-OWG 83-17234

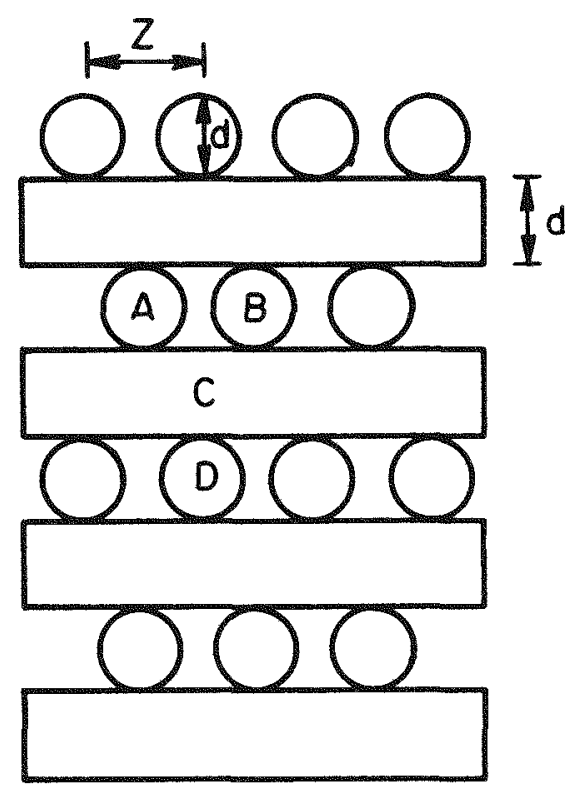

Fig. 8. Idealized packing of fibers with fibers in a plane lying parallel and oriented at right angles in adjacent planes. Fibers are lying in planes perpendicular to the thickness direction of the molded form.

Substituting (6) into (7) yields

$$
\sigma_{c}=\left(\sigma_{f} / \pi \mathbf{r}^{3}\right)\left(\pi d \rho_{f} / 4 \rho\right)^{3},
$$

or

$$
\sigma_{f}=\left(8 / \pi^{2}\right)\left(\rho / \rho_{f}\right)^{3} \sigma_{c},
$$

Equation (9) shows that the compressive strength of $\mathrm{CBCF}$ is proportional to the cube of the bulk density. For a small change in $\rho$ around $p_{O}$,

Eq. (9) yields

$$
\Delta \sigma_{f}=\left(128 / 3 \pi^{3}\right) \sigma_{c}\left(3 \rho_{o}{ }^{2} / \rho f^{3}\right) \Delta \rho \text {. }
$$

For $\mathrm{CBCF}, \sigma_{C}$ is assumed to be $210 \mathrm{MPa}(30 \mathrm{ksi}), \rho_{O}$ is $0.20 \mathrm{Mg} / \mathrm{m}^{3}, \rho_{f}$ is $1.6 \mathrm{Mg} / \mathrm{m}^{3}, \mathrm{Eq} \cdot(10)$ becomes

$$
\Delta \sigma_{f}=8.5 \Delta \rho .
$$


The slope (2.7) of the least-squares fit of compressive strength versus density is in fair agreement with the coefficient (8.5) in Eq. (11). Equation (9) shows that compressive strength increases with increasing bending strength of the carbon fiber if fractures occur only in fibers. In general, the nominal strength and standard deviation of fiber improves as its diameter decreases because of the reduced size of flaws in the fiber. Thus, CBCF parts made of sma11-diameter fibers are expected to be stronger and more consistent in strength than are those made of larger diameter fibers. Equation (9) also explains the increased strength of $\mathrm{CBCF}$ at high temperatures because the strength of rayon carbon fiber typically increases with temperature.

The finding that most of the fiber breakage occurs near the loading surface has important implications. The acoustic velocity in CBCF can be calculated by $\sqrt{E / \rho}$, where $E$ is the elastic modulus and $\rho$ is the bulk density. For $E=14 \mathrm{MPa}$ and $\rho=0.20 \mathrm{Mg} / \mathrm{m}^{3}$, the sonic velocity is about $265 \mathrm{~m} / \mathrm{s}$. Such sonic velocity means rapid load transmission, but the attenuation in CBCF obviously is so high that much of the stress is distributed in the near-surface region. To improve the CBCF strength further, attention should be paid to reducing the sonic attenuation and reinforcing the surface region.

Shear strength of CBCF samples in the thickness direction were measured at room temperature by the ASTM D 732-46 method. The shear strength of $\mathrm{CBCF}$ having a density of $0.20 \mathrm{Mg} / \mathrm{m}^{3}$ is about $0.59 \mathrm{MPa}$ (85 psi), which is less than the compressive strength. The weakness under shear typically found in layered materials such as CBCF is widely known. This problem is genera11y solved by designing to avoid their use in highshear stress conditions.

Long-term creep and load relaxation of several CBCF samples (density, $0.22 \mathrm{Mg} / \mathrm{m}^{3}$ ) in the molding direction were measured at $1000^{\circ} \mathrm{C}$ in argon in anticipation of possible load-bearing applications. ${ }^{6}$ After $10,000 \mathrm{~h}$ at temperature, the stress relaxed to about $71 \%$ of the initial loading of $1.03 \mathrm{MPa}(150 \mathrm{psi}$ ) (ref. 6). The amount of load relaxation in CBCF was much less than those of oxide fibrous insulations such as Min-K under the 
same creep test conditions. This is understandable because porous oxide fibrous insulations undergo sintering and shrink at high temperatures, whereas carbon in the form of fiber or powder is known to be nonsinterable at any temperature.

THERMOPHYSICAL PROPERTIES

Thermophysical properties, including thermal diffusivity, thermal expansion, and emissivity of $\mathrm{CBCF}$, have been measured. Detailed results, published elsewhere, ${ }^{13-14}$ are only briefly summarized here.

The total hemispheric emittance was measured by a direct-heating method. The emissivity in the direction parallel to the fiber array is 0.8 from 1000 to $1800^{\circ} \mathrm{C}$. This is higher than the emissivity $(0.5-0.6)$ of pyrolytic graphite in the C-direction but is close to that $(0.8)$ of 3D C-C.

Thermal expansion of $\mathrm{CBCF}$ was obtained with a quartz-pushrod dilatometer from room temperature to $800^{\circ} \mathrm{C}$ and with a multiproperty apparatus from 800 to $1800^{\circ} \mathrm{C}$. Expansion was greater in the direction perpendicular to fiber array, with an anisotropic factor of 1.4. The mean coefficients of thermal expansion from room temperature to $1800^{\circ} \mathrm{C}$ in the direction perpendicular $\left(3.9 \mathrm{E}-6 /{ }^{\circ} \mathrm{C}\right)$ and parallel $\left(2.8 \mathrm{E}-6 /{ }^{\circ} \mathrm{C}\right)$ to fiber array are lower than those $\left(8.3 \mathrm{E}-6 /{ }^{\circ} \mathrm{C}\right)$ of common graphitic materials such as POCO graphite.

Thermal diffusivity $\alpha$ was obtained with the laser flash diffusivity method. 15 Radiation from the front face of the sample measuring $12.7 \mathrm{~mm}$ in diameter by $2.0 \mathrm{~mm}$ in thickness was corrected by a proportioning technique. 16 The relationship $k=\alpha C_{p} \rho$, where $C_{p}$ is the specific heat and $\rho$ is the density, was used to calculate $k$ (thermal conductivity). The specific heats of 30 samples of $C B C F$ were measured with a differential scanning calorimeter. The $C_{p}$ results were within $2 \%$ of the recommended values for POCO graphite ${ }^{17}$ used in calculating thermal conductivity values from the thermal diffusivity results. As expected, the thermal conductivity of outgassed $\mathrm{CBCF}$ in the direction perpendicular to the fiber array depends on the carbonization temperature. Increasing the carbonization 
temperature from 1350 to $1600^{\circ} \mathrm{C}$ increased the thermal conductivity in vacuum by about $30 \%$. The thermal conductivity of $C B C F$ in vacuum is highly directiona1, with an anisotropic factor of 5 from room temperature to $2000^{\circ} \mathrm{C}$.

More than 45 measurements of the thermal conductivity of $\mathrm{CBCF}$ in the thickness direction were made in vacuum from room temperature to $2000^{\circ} \mathrm{C}$. Samples were from CBCF tubes made in six multimolding runs and from plates fabricated in three molding runs. The thermal conductivity at room temperature ranged from a low of 0.0222 to a high of $0.0863 \mathrm{~W} /\left(\mathrm{m}^{\circ} \mathrm{K}\right)$ for sample densities ranging from 0.20 to $0.25 \mathrm{Mg} / \mathrm{m}^{3}$. Figure 9 shows the thermal conductivity as a function of density for these ranges. A test of linearity ${ }^{18}$ did not disprove the hypothesis that thermal conductivity

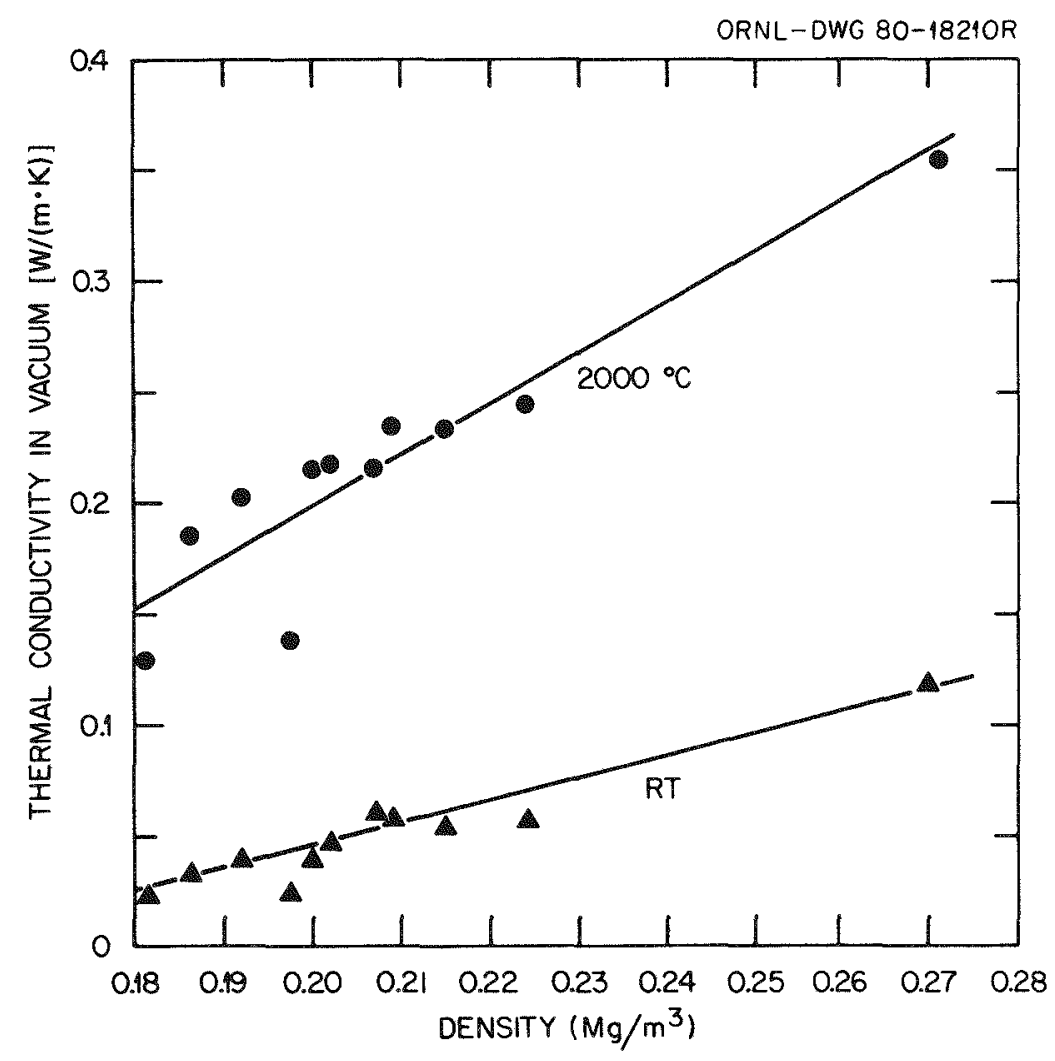

Fig. 9. Density dependence of thermal conductivity of carbon-bonded carbon fiber in the thickness direction in vacuum at room temperature and $2000^{\circ} \mathrm{C}$. 
varies linearly with density. At room temperature, least-squares fit yields

$$
k_{v}\left(25^{\circ} \mathrm{C}\right)=-0.04757+0.5013 \rho,
$$

where $k_{v}$ is the thermal conductivity in vacuum $[\mathrm{W} /(\mathrm{m} \cdot \mathrm{K})]$ and $\rho$ is the density $\left(\mathrm{Mg} / \mathrm{m}^{3}\right)$. At $2000^{\circ} \mathrm{C}$, the density dependence is stronger:

$$
k_{v}\left(2000^{\circ} \mathrm{C}\right)=-0.03936+1.39 p \text {. }
$$

The data are presented in Figs. 10 and 11. The standard deviations for both cases are about $15 \%$.

Baxter derived an expression for fibrous insulation (without binder) in gaseous environment, 19 in which the thermal conductivity $k$ was

$$
k=X\left(k_{f} V_{f}+k_{g} V_{g}\right)+Y\left(k_{g} k_{f}\right) /\left(k_{f} V_{g}+k_{g} V_{f}\right),
$$

where $k_{f}, k_{g}, V_{f}$, and $V_{g}$ represent the thermal conductivity and volume fraction of fiber and gas. In Baxter's model and in other models of thermal conductivity in fibrous insulations presented below, thermal resistance in binders is assumed to be negligible. Baxter found empirically that $X=0.21$ and $Y=0.79$ fit his data obtained for fibrous insulations with densities ranging from 0.3 to $0.6 \mathrm{Mg} / \mathrm{m}^{3}$. Considering vacuum environment and by use of Baxter's coefficients, Eq. (14) gives a linear relationship between thermal conductivity and density,

$$
k=0.21 k_{f} \rho / \rho_{f},
$$

where $\rho$ is the bulk density and $\rho_{f}$ the fiber density. Hager and Steere derived the following relationships for the total conductivity $k_{v}$ of fibrous insulation in vacuum, 20 which was the sum of the solid $k_{S}$ and radiation $k_{r}$ conductivity,

$$
\begin{aligned}
& k_{v}=k_{s}+k_{r}, \\
& k_{s}=4 k_{f} \rho / \rho_{f}, \\
& k_{r}=4 \sigma d T^{3} \rho_{f} / \rho,
\end{aligned}
$$




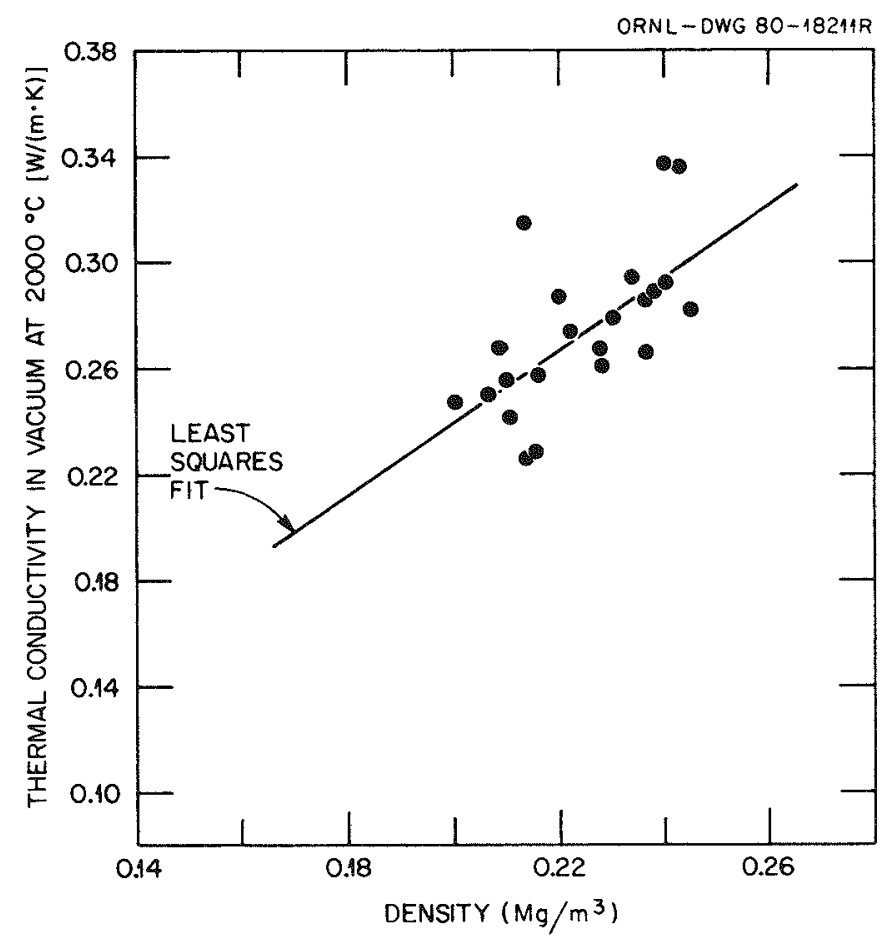

Fig. 10. Therma1 conductivity of carbon-bonded carbon fiber at $2000^{\circ} \mathrm{C}$ in vacuum as a function of density.

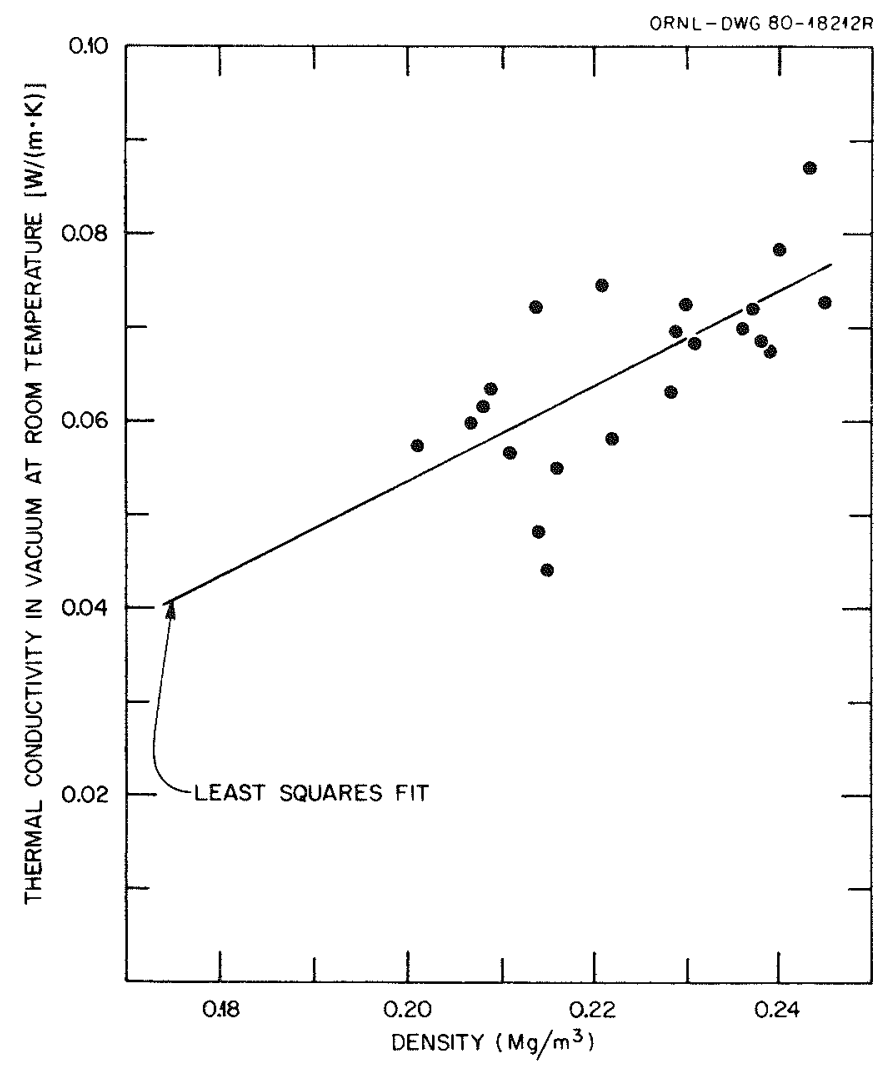

Fig. 11. Thermal conductivity of carbon-bonded carbon fiber at room temperature in vacuum as a function of density. 
where $\sigma$ is the Stefan radiation constant, $d$ the fiber diameter, and $T$ the absolute temperature. Equations (16) through (18) suggest that, at low temperatures where $k_{r} \ll k_{s}$, the conductivity varies 1inearly with density. Verschoor and Greenbler also modeled heat transfer in fibrous insulation by comparing theory with experimental data. 21 They obtained

$$
\begin{aligned}
& k_{v}=k_{s}+k_{p} \rho /\left(\rho_{f}-\rho\right), \\
& k_{p}=2.15 \mathrm{E}-13 \rho_{f} d T^{3} / \alpha^{2} \rho,
\end{aligned}
$$

in English units, where $\alpha$ is an "opacity" factor or the fraction of incident radiant energy absorbed by a fiber. Equations (16) through (18) (Harger and Steere) 20 and Eqs. (19) and (20) (Vershoor and Greenbler) 21 all suggest that the conductivity at high temperatures would increase with increasing fiber diameter and decreasing density if $k_{r} \gg k_{g}$. In view of these analytical models, the positive slope of $k$ vs $\rho$ at $2000^{\circ} \mathrm{C}$ shown in Fig. 9 suggests that at $2000^{\circ} \mathrm{C}$ the solid conductivity is still appreciable.

Donaldson established a more rigorous model for heat transfer in carbon fiber insulation by assuming parallel heat flow paths, including solid conduction, gas conduction, and radiation. 22 Assuming that the thermal resistance of the carbon binder was negligible, he derived the following equation for thermal conductivity $k_{c}$ resulting from solid and gas conduction

$$
k_{c}=\alpha\left[\varepsilon_{p} k_{g}+\left(1-\varepsilon_{p}\right) k_{f}\right]+(1-\alpha) k_{f t} k_{g} /\left[\left(1-\varepsilon_{s}\right) k_{g}+\varepsilon_{s} k_{f}\right],
$$

where

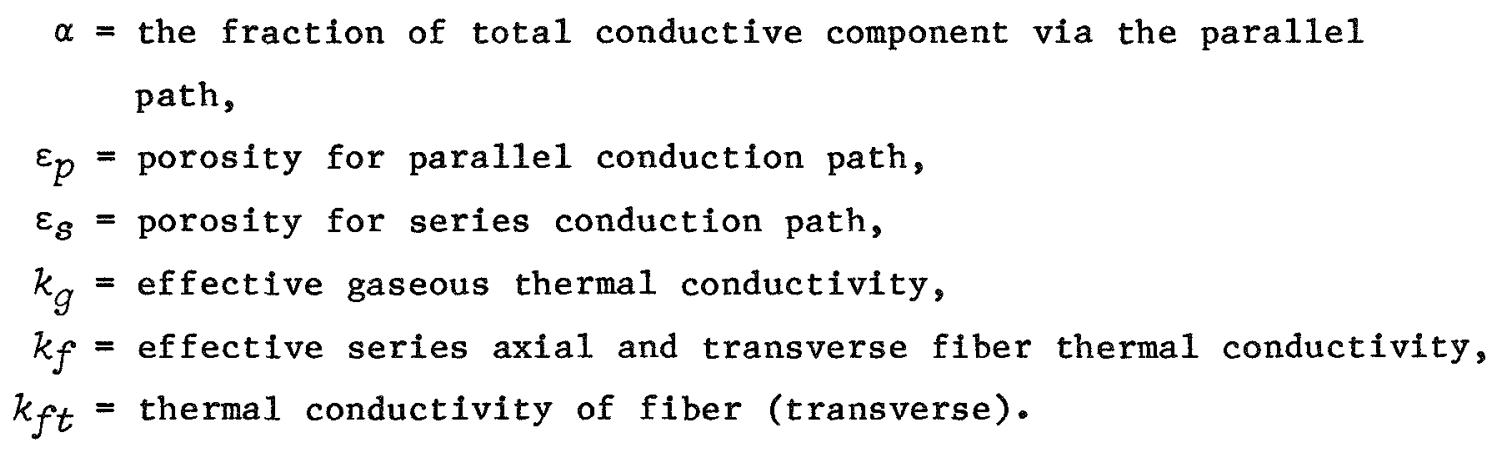


The first term in Eq. (21) represents parallel gas and solid conduction, and the second term is total series gas and solid conduction. Under vacuum, Eq. (21) shows that the solid conductivity is

$$
k_{s}=\alpha\left(1-\varepsilon_{p}\right) k_{f} \text {. }
$$

Considering geometric arrangement of the fibers (Fig. 8), the following relationships were derived 22 for estimating $a, \varepsilon_{p}, \varepsilon_{g}$, and $k_{f}$ :

$$
\begin{gathered}
a=\left[(Z-d)^{2}+d^{2}\right] / Z^{2}, \\
\varepsilon_{p}=\left[(Z-d)^{2}\right] / Z^{2}, \\
\varepsilon_{s}=\left(P-\alpha \varepsilon_{p}\right) /(1-\alpha), \\
k_{f}=k_{f t} k_{f a} /\left(k_{f t} Z / 4 d+k_{f a}\right), \\
Z=\pi d /[4(1-P)],
\end{gathered}
$$

where

$$
\begin{aligned}
Z & =\text { the distance between fibers in a fiber plane, } \\
P & =C B C F \text { porosity, } \\
k_{f a} & =\text { thermal conductivity of fiber (axial). }
\end{aligned}
$$

Substituting Eqs. (23) through (27) into Eq. (22), the solid conductivity becomes

$$
k_{s}=\frac{d\left[(z-d)^{2}+d^{2}\right](2 z-d)}{z^{4}} \cdot \frac{k_{f t} k_{f a}}{k_{f t} z / 4 d+k_{f a}} .
$$

Since $P=1-\rho / \rho_{f}$ and $\rho_{f}=1.6 \mathrm{Mg} / \mathrm{m}^{3}, \mathrm{Eq} \cdot$ (27) leads to

$$
Z=1.26 d / \rho \text { or } \quad d / Z=0.80 \rho \text {, }
$$

where $\rho$ is in units of $\mathrm{Mg} / \mathrm{m}^{3}$.

Since the fiber spacing of $\mathrm{CBCF}$ is much greater than the fiber diameter $(Z \gg d)$ and the thermal conductivity of fiber is approximately isotropic because of the amorphous state of the carbon fiber 
$\left(k_{f} \approx k_{f t} \approx k_{f}\right)$, by neglecting second and higher orders of $d / z$ in $\mathrm{Eq} \cdot(28)$, we may show that

$$
k_{s}=5.1 k_{f} \rho^{2} /(1+3.2 \rho) \text {. }
$$

Equation (30) holds true for a wide range of $\rho$. For a small range of $\rho$, taking the derivative gives

$$
\Delta k_{s} / \Delta \rho=\left(10 \rho+16.3 \rho^{2}\right) /(13.2 \rho)^{2} k_{f} \text {. }
$$

For $\mathrm{CBCF}$, nominal $\rho=0.21 \mathrm{Mg} / \mathrm{m}^{3}, k_{f}$ is assumed to be $1.0 \mathrm{~W} /(\mathrm{m} \cdot \mathrm{K})$ at room temperature in vacuum, ${ }^{22} \mathrm{Eq}$. (31) yields a slope of 1.0 ( $k_{s}$ vs $\rho$ ), which is in fair agreement with the observed coefficient ( $k$ vs $\rho$ ) in Eq. (12) considering the assumption of perfect fiber contact, right-angle array, and uncertainty in $k_{f}$. Equation (31) shows that the slope is proportional to $k_{f}$, which increases with temperature. The higher density dependence at higher temperatures (Fig. 9) can thus be explained by (1) solid conduction dominates, (2) the relationship between the slope and $k_{f}$ shown in Eq. (31), and (3) $k_{f}$ increases with temperature. For $\rho=0.21 \mathrm{Mg} / \mathrm{m}^{3}$, $k_{f}=1 \mathrm{~W} /(\mathrm{m} \cdot \mathrm{K})$ at $25^{\circ} \mathrm{C}$ (ref. 22) and $6.3 \mathrm{~W} /\left(\mathrm{m} \cdot \mathrm{K}\right.$ ) at $2000^{\circ} \mathrm{C}$ (ref. 23), $\mathrm{Eq} \cdot(30)$ shows a solid conductivity of $0.12 \mathrm{~W} /(\mathrm{m} \cdot \mathrm{K})$ at $25^{\circ} \mathrm{C}$ and $0.78 \mathrm{~W} /(\mathrm{m} \cdot \mathrm{K})$ at $2000^{\circ} \mathrm{C}$. Both values are theoretical upper limits because of the assumed perfect fiber contact. These theoretical values are greater than the experimental values $\left[\sim 0.06 \mathrm{~W} /(\mathrm{m} \cdot \mathrm{K})\right.$ at $25^{\circ} \mathrm{C}$ and $\sim 0.28 \mathrm{~W} /(\mathrm{m} \cdot \mathrm{K})$ at $\left.2000^{\circ} \mathrm{C}\right]$.

Equation (20) is used for estimating $k_{p}$. For $\mathrm{CBCF}, \rho=0.21 \mathrm{Mg} / \mathrm{m}^{3}$, $\rho_{f}=1.6 \mathrm{Mg} / \mathrm{m}^{3}, d=7 \mathrm{~km}$, and assuming $\alpha=6$ (ref. 21), Eq. (20) yields

$$
k_{r}=4.6 \mathrm{E}-14 \mathrm{~T}^{3} \mathrm{~W} /(\mathrm{m} \cdot \mathrm{K}) \text {. }
$$

At $25^{\circ} \mathrm{C}, k_{p}=1.2 \mathrm{E}-6 \mathrm{~W} /\left(\mathrm{m}^{\circ} \mathrm{K}\right)$, and at $2000^{\circ} \mathrm{C}, k_{p}=0.54 \mathrm{E}-3 \mathrm{~W} /\left(\mathrm{m}^{\circ} \mathrm{K}\right)$. These values suggest that, even at $2000^{\circ} \mathrm{C}$, radiation is not the dominant mode of heat transfer in $\mathrm{CBCF}$.

The important implications of $\mathrm{Eq} \cdot(20)$ are that, to further reduce $k_{r}$, the fiber diameter $d$ must be decreased and "opacity" $\alpha$ must be increased. Graphite flakes have been incorporated into CBCF insulation as opacifiers to reduce thermal conductivity at ultrahigh temperatures $\left(>2250^{\circ} \mathrm{C}\right)$, but thermal conductivity at temperatures lower than $2250^{\circ} \mathrm{C}$ was 
increased with the opacifier doping. ${ }^{2}$ In principle, SiC particles could be more effective opacifiers because of the large difference in the index of refraction between $\mathrm{SiC}$ and carbon.

Least-squares fit of 46 data points (21 at room temperature, 21 at $2000^{\circ} \mathrm{C}, 2$ at $800^{\circ} \mathrm{C}$, and 2 at $1400^{\circ} \mathrm{C}$ ) of thermal conductivity in the thickness direction in vacuum of $C B C F$ with densities ranging from 0.201 to $0.245 \mathrm{Mg} / \mathrm{m}^{3}$ showed the following relationship:

$$
\begin{aligned}
k & =-0.06988+7.543 \mathrm{E}-5 T-1.200 \mathrm{E}-11 \mathrm{~T}^{3} \\
& +\left(0.4364+2.128 \mathrm{E}-4 \mathrm{~T}+4.000 \mathrm{E}-11 \mathrm{~T}^{3}\right),
\end{aligned}
$$

where

$$
\begin{aligned}
& k=\text { thermal conductivity }[\mathrm{W} /(\mathrm{m} \cdot \mathrm{K})] \\
& T=\text { absolute temperature, } \\
& \rho=\text { density }\left(\mathrm{Mg} / \mathrm{m}^{3}\right) .
\end{aligned}
$$

The $T$ term represents solid conduction through fibers and binders, and the $T^{3}$ term, the radiation portion of the conductivity. The temperature dependence of the thermal conductivity for three densities is shown in Fig. 12. Equation (33) was derived primarily for use in the design of the GPHS .

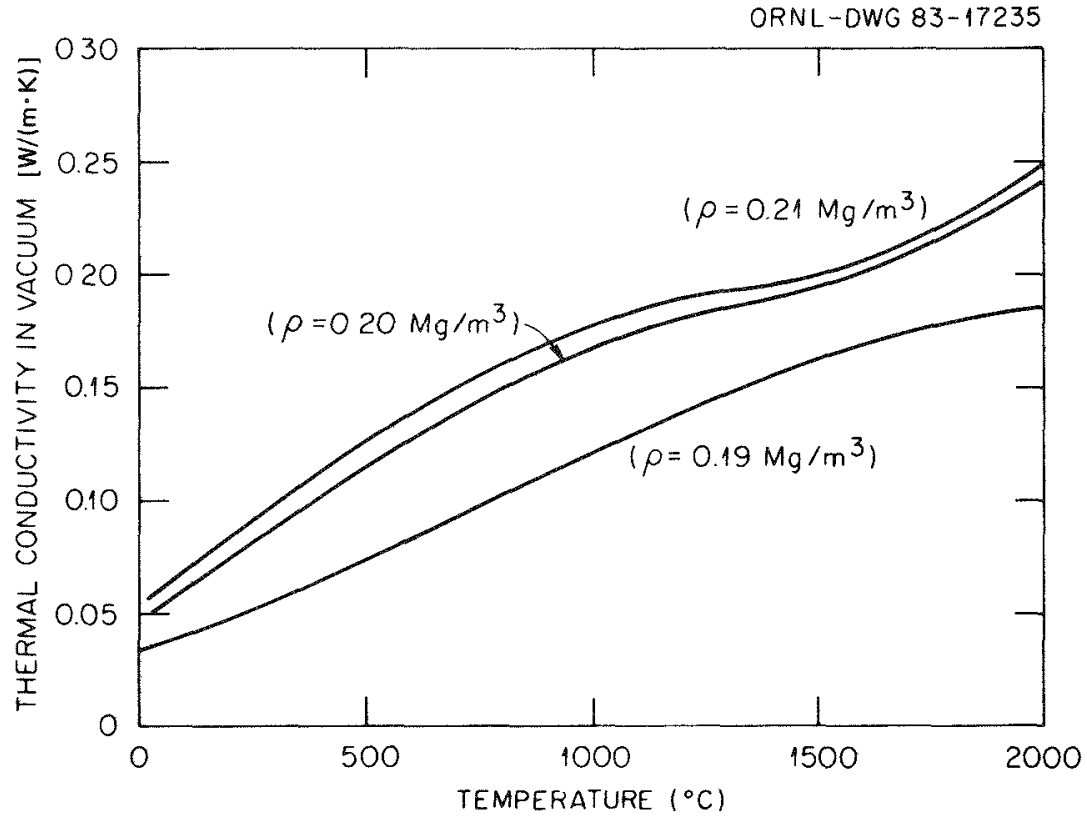

Fig. 12. Thermal conductivity of carbon-bonded carbon fiber in the thickness direction in vacuum as a function of temperature. 
The thermal conductivities of some samples were determined in air and in nitrogen as well as in vacuum. The values obtained in a gaseous environment were significantly larger than those measured in vacuum, as expected. For example, the thermal conductivity of $\mathrm{CBCF}$ in the direction perpendicular to the fiber array in $101 \mathrm{kPa} \mathrm{N} \mathrm{N}_{2}$ was 3 times that in vacuum. The increased conductivity values correlated well with the increases expected on the basis of the conductivity of the gas and of $C B C F$ and the relative volumes of gas and solids in $\mathrm{CBCF}$ (ref. 13). Thermal conductivities of $\mathrm{CBCF}\left(0.25 \mathrm{Mg} / \mathrm{m}^{3}\right)$ in helium and xenon were also determined by a guarded hot plate method. 24 For thermal conductivity in the thickness direction of $\mathrm{CBCF}$ in $0.1 \mathrm{MPa}$ ( $1 \mathrm{~atm}$ ) $\mathrm{N}_{2}$, the following relationship was derived from data for two densities $\left(0.19\right.$ and $\left.0.25 \mathrm{Mg} / \mathrm{m}^{3}\right)$ by assuming that gas conductivity varies with the square root of temperature and linearly with density under $0.1 \mathrm{MPa} \mathrm{N}_{2}$,

$$
\begin{aligned}
k_{N}= & -0.06988+7.543 \mathrm{E}-5 T-1.200 \mathrm{E}-11 T^{3} \\
& +\left(0.4364+2.128 \mathrm{E}-4 T+4.000 \mathrm{E}-11 T^{3}\right) \rho \\
& +[3.816 \mathrm{E}-3+1.7807 \mathrm{E}-2(\rho-0.19)] T^{1 / 2},
\end{aligned}
$$

where $k_{N}$ is thermal conductivity of $\mathrm{CBCF}$ in $0.1 \mathrm{MPa}$ or $1.0 \mathrm{~atm} \mathrm{~N}_{2}$ $[\mathrm{W} /(\mathrm{m} \cdot \mathrm{K})]$. Equation (34) was for use in calculating temperature profiles in the GPHS module during reentry as air gradually diffuses into the system.

Thermal conductivity as a function of nitrogen pressure was determined, and results are shown in Fig. 13. The data in Fig. 13 show a gradual change in the thermal conductivity, with the highest rate of change at about $1.0 \mathrm{kPa}$ pressure at $1800^{\circ} \mathrm{C}$. The corresponding mean free path of nitrogen is $52 \mu \mathrm{m}$, which is very close to the fiber spacing $(55 \mu \mathrm{m})$ in $\mathrm{CBCF}$. 
ORNL-DWG 83-17237

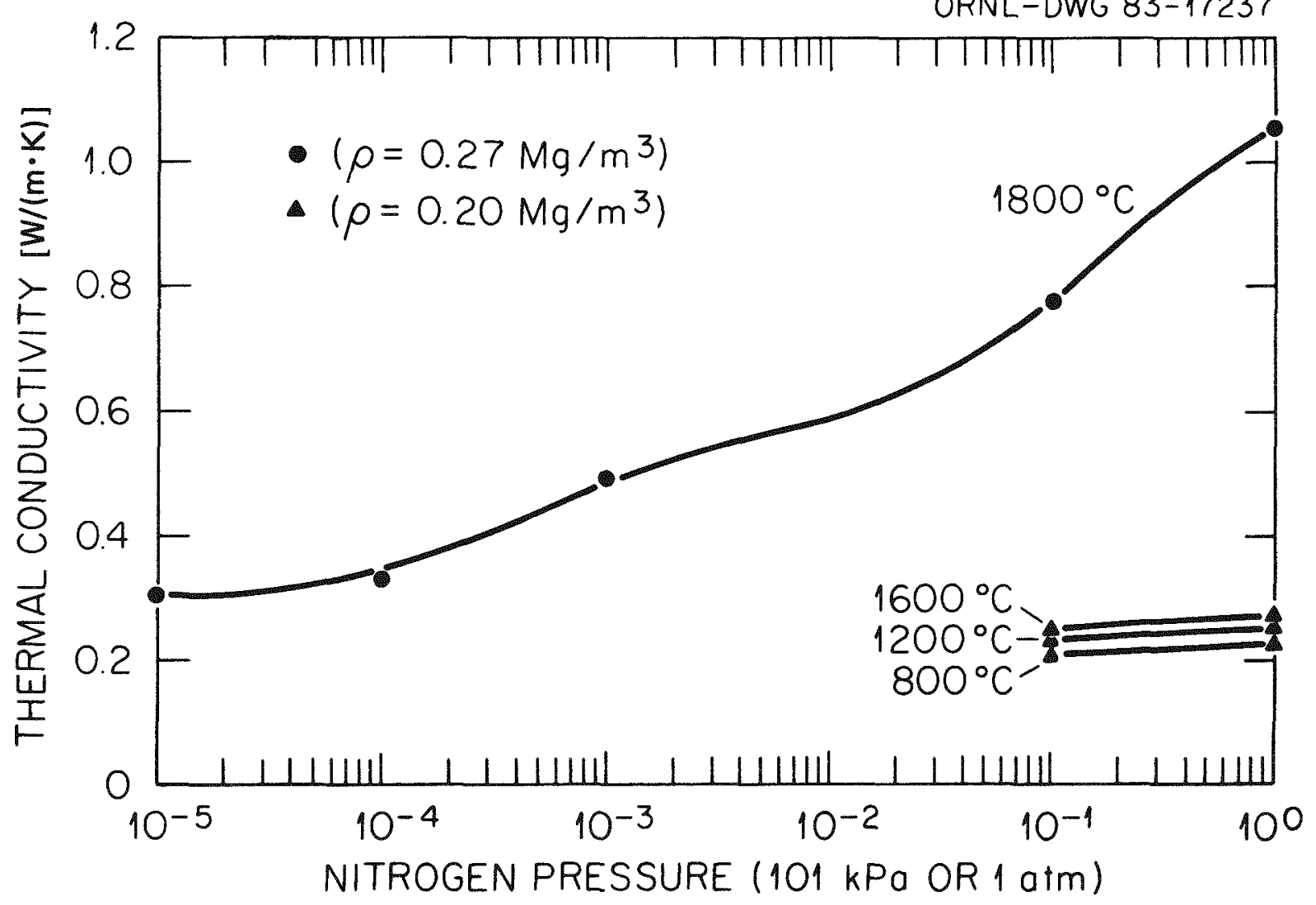

Fig. 13. Thermal conductivity of carbon-bonded carbon fiber in the thickness direction in nitrogen.

\section{CONCLUSIONS: ATTRIBUTES AND APPLICATIONS}

$A$ rayon-base $C B C F$ insulation has been developed and selected for use in high-reliability space nuclear power systems. The CBCF sleeves and disks are produced by carbonizing cured shapes vacuum molded from water slurries of carbon fiber and phenolic resin. Process improvements were made to eliminate large pores and axial cracking typically found in parts made by the old process. A multimandrel facility demonstrated a ten-times faster fabrication and considerable fabrication cost reduction. Critical processing parameters including fiber length, length distribution, binder content, curing rate, and carbonization temperature influencing the properties of the fabricated parts were studied. 
The CBCF is an excellent insulation among all known thermal insulations. Although its thermal conductivity increases with temperature, it is one-third that of pyrolytic graphite in the C-direction, even at $2000^{\circ} \mathrm{C}$ in vacuum. At $800^{\circ} \mathrm{C}$, the difference is one order of magnitude (Fig. 14). Relative to other oxide fibrous insulations such as Cotronics, * Fiberfrax, and Zircar, $\mathrm{CBCF}$ has slightly higher conductivities at low temperatures but is usable over much wider and higher temperatures (Fig. 14). Oxide fibrous insulations are incompatibile with graphites commonly used in radioisotope space nuclear systems, and multifoil insulation whose thermal conductivity is lower than that of $\mathrm{CBCF}$ (ref. 25) is too heavy to be

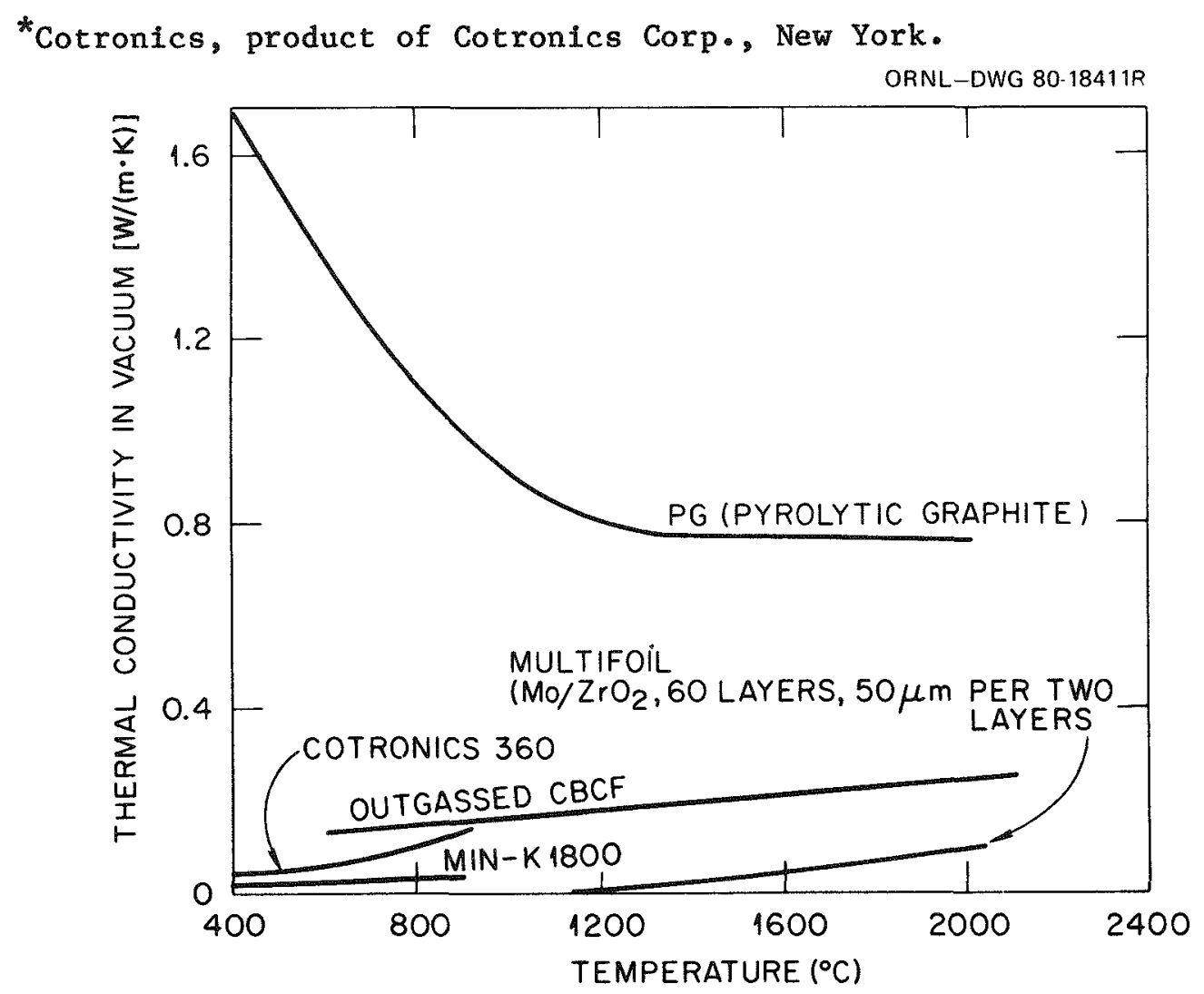

Fig. 14. Thermal conductivity of various thermal insulations in vacuum as a function of temperature. Sources of data: CBCF, R. E. Taylor, H. Groot, and R. L. Shoemaker, Thermophysical Properties of Carbon Insulation, TPRL 196, Thermophysical Properties Research Laboratory, Purdue University, Lafayette, Ind., 1979; Min-K 1800 and Cotronics 360, E. A. Skrabek, "High-Temperature Insulations for Radioisotope Thermoelectric Generators," pp. 1712-76 in Proceedings of 13 th Intersociety Energy Conversion and Engineering Conference, held in San Diego, Calif., on Aug. 20-25, 1978, vol. 2, American Society of Mechanical Engineers, New York, 1978; pyrolytic graphite and multifoil, H. Sookiazian, Fairchild Industries, Germantown, Md., personal communication to G. C. Wei, January 1980. 
favorably considered for use in the GPHS. A proper outgassing procedure was established for the use of $\mathrm{CBCF}$ in the GPHS. It is chemically pure carbon and compatible with other graphites and refractory metals in the GPHS. The strength was satisfactory; CBCF passed the vigorous GPHS vibration tests. These attributes led to the application of CBCF in the GPHS. Because of the relative low density $\left(0.2 \mathrm{Mg} / \mathrm{m}^{3}\right.$ vs $2 \mathrm{Mg} / \mathrm{m}^{3}$ for pyrolytic graphite), $\mathrm{CBCF}$ is lightweight. Its low thermal conductivity enables the use of only a very small thickness $(2 \mathrm{~mm})$. The application of CBCF in the GPHS reduces the weight of the overal1 system by $1.4 \mathrm{~kg}$ and successfully increases the specific power by a significant $7 \%$ (ref. 1) over previous space nuclear power systems or other designs of the GPHS utilizing contemporary insulations.

\section{ACKNOWLEDGMENTS}

The authors are grateful to the following ORNL personnel who have made valuable contributions to the work described in this report: C. Hamby for fabrication, R. S. Crouse for scanning electron microscopy, K. C. Liu for cyclic fatigue tests, L. Landau for chemical analysis, and B. E. Foster for X-radiography. The authors also thank P. F. Becher and D. W. Yarbrough for reviewing the manuscript, Sigfred Peterson and Irene Brogden for editing the manuscript, and Patricia Wilson for final manuscript preparation.

\section{REFERENCES}

1. A. Schock, "Design Evolution and Verification of the GeneralPurpose Heat Source," pp. 1032-42 in Proceedings of 15th Intersociety Energy Conversion and Engineering Conference, held in Seattle, Wash., on Aug. 18-22, 1980, vol. 2, American Society of Mechanical Engineers, New York, 1980.

2. Z. L. Ardary and C. D. Reynolds, Carbon-Fiber Thermal Insulation, Y-1803, Oak Ridge Y-12 P1ant, Oak Ridge, Tenn., 1972.

3. C. D. Reynolds and Z. L. Ardary, Low-Density Carbon Fiber Composites, Y/DA-6925, Oak Ridge Y-12 Plant, Oak Ridge, Tenn., 1976. 
4. J. L. Cook, "Discontinuous Carbon/Carbon Fabrication Processes," pp. 143-72 in Proceedings of the 10th Annual Symposium of the New Mexico Section of $A S M E$, held in Albuquerque, N.M., in January 1970, American Soclety of Mechanical Engineers, Albuquerque, N.M•, 1970.

5. D. P. Kelly and V. L. Avona, Appolo Lunar Radioisotopic Heater Summary Report, MLM-1637, Mound Laboratory, Miamisburg, Ohio, 1969, p. 8.

6. W. E. Osmeyer, pP. VII-50-58 in Selenide Isotope Generator for the Galizeo Mission, Program Final Report, TES-33009-46, Teledyne Energy Systems Co., Timonium, Md., June 1979.

7. S. Chow and P. R. Steiner, "Comparisons of the Cure of Pheno1Formaldehyde Novalac and Resol Systems by Differential Scanning Calorimetry," J. Appl. Poly. Sci. 23, 1973-85 (1979).

8. B. E. Foster, Oak Ridge National Laboratory, personal communication to G. C. Wei, Apri1 1980.

9. W. M. Pardue, A Critical Review of the Materials Selection Program for the Transit and Pioneer Heat Source, BMI-X-645, Battelle Columbus Laboratory, Columbus, Ohio, 1973.

10. G. C. Wei, "Outgassing of Carbon-Bonded Carbon Fiber Insulation," pp. 249-50 in 14th Biennial Conference on Carbon, Extended Abstracts and Program, held in University Park, Pa., on June 25-29, 1979, The Pennsylvania State University, 1979.

11. J. V. Milewski, "The Combined Packing of Rods and Spheres in Reinforcing Plastics," Ind. Eng. Chem. Prod. Res. Dev. 17(4), 263-366 (1978).

12. R. H. Cooper, Oak Ridge National Laboratory, personal communication to G. C. Wei, December 1980.

13. R. E. Taylor, H. Groot, and R. L. Shoemaker, Thermophysical Properties of Carbon Insulation, TPRL 196, Thermophysical Properties Research Laboratory, Purdue University, Lafayette, Ind., 1979.

14. R. E. Taylor and H. Groot, Thermophysical Properties of CBCF3, TPRL 228, Thermophysical Properties Research Laboratory, Purdue University, Lafayette, Ind., December 1981.

15. R. E. Taylor, "Heat-Pulse Thermal Diffusivity Measurements," High Temp. High Pressures 11, 43-48 (1979). 
16. L. M. Clark and R. E. Taylor, "Radiation Loss in the Flash Method for Thermal Diffusivity, J. Appl. Phys. 46(2), 714-19 (1975).

17. M. S. Deshpande and R. H. Boggard, "Evaluation of Specific Heat Data for POCO Graphite and Carbon-Carbon Composites," pp. 45-54 in Proceedings of 17 th Intemational Thermal Conductivity Conference, held in Gaithersburg, Md., on June 15-18, 1981, Plenum Press, New York, 1983.

18. M. G. Natre11a, ed., "Experimental Statistics," pp. 5-22 in NBS Handbook 91, National Bureau of Standards, Gaithersburg, Md., 1963.

19. S. Baxter, "The Thermal Conductivity of Textiles," Proc. Phys. Soc., London 58, 105 (1946).

20. N. E. Hager and R. C. Steere, "Radiant Heat Transfer in Fibrous Thermal Insulation," J. Appl. Phys. 38(12), 4663-68 (1967).

21. J. D. Verschoor and P. Greenbler, "Heat Transfer by Gas Conduction and Radiation in Fibrous Insulations," Trans. ASME 74, 961-68 (1952).

22. A. B. Donaldson, "The Effect of Radiation Barriers on Heat Transfer Through Carbon Fiber Insulation," paper 73-HT-44 presented at the ASME-AIChE Heat Transfer Conference, held in Atlanta, Ga., August 1973.

23. T. G. Godfrey, D. L. McE1roy, and Z. L. Ardary, "Thermal Conductivity of Oriented Fibrous Carbon Insulation from 300 to $1300 \mathrm{~K}$ in Nitrogen and Argon at One Atmosphere," Nucl. Technol. 22, 94-107 (1974).

24. E. A. Skrabek, "High-Temperature Insulations for Radioisotope Thermoelectric Generators," pp. 1712-76 in Proceedings of 13 th Intersociety Energy Conversion and Engineering Conference, held in San Diego on Aug. 20-25, 1978, vol. 2, American Society of Mechanical Engineers, New York, 1978.

25. H. Sookiazian, Fairchild Industries, Germantown, Md., personal communication to G. C. Wei, January 1980. 
BLANK 
ORNL/TM-9381

Distribution

Category UC-25

\section{INTERNAL DISTRIBUTION}

1-2. Central Research Library

3. Document Reference Section

4-5. Laboratory Records Department

6. Laboratory Records, ORNL RC

7. ORNL Patent Section

8. P. Angelini

9. E. E. Bloom

10. A. J. Caputo

11. J. A. Carter

12. R. H. Cooper

13. W. P. Eatherly

14. C. Hamby, Jr.

15. W. 0. Harms

16. M. A. Janney

17. D. R. Johnson

18. J. R. Keiser

19. M. M. Martin

20. R. W. McClung
21. D. L. McElroy

22. A. J. Moorhead

23. R. E. Pawe1

24-28. J M Robbins

29. A. C. Schaffhauser

30. J. L. Scott

31. G. M. Slaughter

32. V. J. Tennery

33-35. P. T. Thornton

36. T. N. Tiegs

37. F. W. Wiffen

38. R. J. Charles (Consultant)

39. H. F. Cook (Consultant)

40. Alan Lawley (Consultant)

41. T. B. Massalski (Consultant)

42. J. C. Williams (Consultant)

43. K. M. Zwilsky (Consultant)

EXTERNAL DISTRIBUTION

44. AMES LABORATORY, Iowa State University, 242 Spedding Ha11, Ames, IA 50011

B. J. Beaudry

45. AIR FORCE WEAPONS LABORATORY/NTXR, Kirtland Air Force Base, NM 87117

J. D. Martens

46. BATTELLE COLUMBUS LABORATORIES, 505 King Ave., Columbus, OH 43201 C. A. Alexander

47. E.I. du PONT de NEMOURS, Savannah River Plant, Aiken, SC 29801

J. K. Brown

48. FAIRCHILD INDUSTRIES, 20301 Century Blvd., Germantown, MD 20767

A. Schock

49. GENERAL ELECTRIC COMPANY, Advanced Energy Programs Department, P.0. Box 527, Bullding B, King of Prussia, PA 19406

R. F. Hartman 
50-54. GTE LABORATORIES, 40 Sylvan Road, Waltham, MA 02154

G. C. WeI

55. JET PROPULSION LABORATORY, California Institute of Technology, 4800 Oak Grove Drive, Pasadena, CA 91103

R. W. Campbe11

56. JOHNS HOPKINS UNIVERSITY, Applied Physics Laboratory, Johns Hopkins Road, Laurel, MD 20810

J. C. Hagan

57. LOS ALAMOS NATIONAL LABORATORY, P.0. Box 1663, Los Alamos, NM 87545

R. W. Zocher

58. MONSANTO RESEARCH CORPORATION, Mound Plant, P.0. Box 32 , Building 88, Miamisburg, OH 45342

W. R. Amos

59. TELEDYNE ENERGY SYSTEMS, 110 W. Timonium Road, Timonium, MD 21093

P. Dick

60. THERMO ELECTRON CORPORATION, 84 First Avenue, P.0. Box 459, Waltham, MA 02254

P. J. Drivas

61. DOE, ALBUQUERQUE OPERATIONS OFFICE, P.0. Box 5400, Albuquerque, NM 87115

D. L. Krenz

62. DOE, DAYTON AREA OFFICE, P.0. BOx 66, Miamisburg, OH 45342

G. P. Gartre11

63. DOE, OAK RIDGE OPERATIONS OFFICE, P.O. BOX E, Oak Ridge, TN 37831

Office of Assistant Manager for Energy Research and Development

64. DOE, OFFICE OF SPACE NUCLEAR PROJECTS, NE-55, MS B-435, Washington, DC 20545

W. J. Barnett

65. DOE, SAN FRANCISCO OPERATIONS OFFICE, 1333 Broadway, Wells Fargo Building, Oakland, CA 94612

W. L. Von Flue 
66. DOE, SAVANNAH RIVER OPERATIONS OFFICE, P.O. Box A, Aiken, SC 29801 G. M. Nichols

67-246. DOE, TECHNICAL INFORMATION CENTER, P.0. Box 62, Oak Ridge, TN 37831

For distribution as shown in DOE/TIC-4500, Distribution Category UC-25 (Materlals). 